Evaluation of Cavity Collapse and Surface Crater Formation for Selected Lawrence Livermore National Laboratory Underground Nuclear Tests - 2007

S. K. Roberts, G. A. Pawloski, K. Raschke

May 10, 2010 
This document was prepared as an account of work sponsored by an agency of the United States government. Neither the United States government nor Lawrence Livermore National Security, LLC, nor any of their employees makes any warranty, expressed or implied, or assumes any legal liability or responsibility for the accuracy, completeness, or usefulness of any information, apparatus, product, or process disclosed, or represents that its use would not infringe privately owned rights. Reference herein to any specific commercial product, process, or service by trade name, trademark, manufacturer, or otherwise does not necessarily constitute or imply its endorsement, recommendation, or favoring by the United States government or Lawrence Livermore National Security, LLC. The views and opinions of authors expressed herein do not necessarily state or reflect those of the United States government or Lawrence Livermore National Security, LLC, and shall not be used for advertising or product endorsement purposes.

This work performed under the auspices of the U.S. Department of Energy by Lawrence Livermore National Laboratory under Contract DE-AC52-07NA27344. 


\title{
Evaluation of Cavity Collapse and Surface Crater Formation for Selected Lawrence Livermore National Laboratory Underground Nuclear Tests - 2007
}

\author{
Sarah Roberts \\ Gayle Pawloski \\ Energy and Environment Directorate \\ Kenneth Raschke \\ Chemistry and Material Life Sciences Directorate
}

May 1, 2007

Lawrence Livermore National Laboratory

Livermore, CA 94551 


\section{Evaluation of Cavity Collapse and Surface Crater Formation for Selected Lawrence Livermore National Laboratory Underground Nuclear Tests - 2007}

This report describes evaluation of collapse evolution for selected LLNL underground nuclear tests at the Nevada Test Site (NTS). The work is being done at the request of NSTec and supports the Department of Energy National Nuclear Security Association Nevada Site Office Borehole Management Program (BMP). The primary objective of this program is to close (plug) weapons program legacy boreholes that are deemed no longer useful. Safety decisions must be made before a crater area, or potential crater area, can be reentered for any work. Our statements on cavity collapse and crater formation are input into their safety decisions.

The BMP is an on-going program to address hundreds of boreholes at the NTS. Each year NSTec establishes a list of holes to be addressed. They request the assistance of the Lawrence Livermore National Laboratory and Los Alamos National Laboratory Containment Programs to provide information related to the evolution of collapse history and make statements on completeness of collapse as relates to surface crater stability. These statements do not include the effects of erosion that may modify the collapse craters over time. They also do not address possible radiation dangers that may be present.

Subject matter experts from the LLNL Containment Program and the Chemical Sciences Division who had been active in weapons testing activities performed these evaluations. Information used included drilling and hole construction, emplacement and stemming, timing and sequence of the selected test and nearby tests, geology, yield, depth of burial, collapse times, surface crater sizes, cavity and crater volume estimations, and ground motion. Both classified and unclassified data were reviewed. Various amounts of information are available for these tests, depending on their age and other associated activities. Lack of data can hamper evaluations and introduce uncertainty. We make no attempt to quantify this uncertainty.

The following unclassified summary statements describe collapse evolution and crater stability in response to the 2007 request to review 20 LLNL test locations in areas 2, 9 and 10 of Yucca Flat listed in Table 1 below. 
Table 1. Test locations investigated for closure

\begin{tabular}{|l|l|l|}
\hline Hole Name/Number & Test Name & Test Date \\
\hline U9ay & Oconto & $1 / 23 / 1964$ \\
\hline U9bc & Hook & $4 / 14 / 1964$ \\
\hline U9bf & Links & $7 / 23 / 1964$ \\
\hline U9d & Brazos & $3 / 8 / 1962$ \\
\hline U9i & Anacostia & $11 / 27 / 1962$ \\
\hline U9m & Eel & $5 / 19 / 1962$ \\
\hline U9q & Roanoke & $10 / 12 / 1962$ \\
\hline U9u & Raritan & $9 / 6 / 1962$ \\
\hline U9v & Sacramento & $6 / 30 / 1962$ \\
\hline U9x & Allegheny & $9 / 29 / 1962$ \\
\hline U2eq & Riola & $9 / 25 / 1980$ \\
\hline U9ad & Mississippi & $10 / 5 / 1962$ \\
\hline U9ag & No test & Hole in Terrine-White crater \\
\hline U9ao & Fore & $1 / 16 / 1964$ \\
\hline U9ax & Greys & $11 / 22 / 1963$ \\
\hline U9b & White & $5 / 25 / 1962$ \\
\hline U9p & Black & $4 / 27 / 1962$ \\
\hline U9z & York & $8 / 24 / 1962$ \\
\hline U10e & Klickitat & $2 / 20 / 1964$ \\
\hline U10g & Casselman & $2 / 8 / 1963$ \\
\hline
\end{tabular}

An USGS map depicting surface effects and nearby holes is included after each hole description. 


\section{Oconto \\ U9ay}

The LLNL sponsored Oconto test was detonated in hole U9ay on 1/23/1964. Oconto had an announced yield of $10.5 \mathrm{kt}$ (DOE/NV-209-Rev 15). It was detonated in tuff at a working point of $264 \mathrm{~m}$ below the surface. U9ay is located in central Area 9 between the Yucca Fault to the west and the Area 9 Fault to the east. U9ay is just south of the Area 9 ITS region. Figure 1 shows nearby holes and surface effects. Nearby tests include: Codsaw in U9g on 2/19/1962; Hoosic in U9j on 3/28/1962; Tioga in U9f on 10/18/1962; Manatee in U9af on 12/14/1962; Hatchie in U9e on 2/8/1963; Apshapa in U9ai on 6/6/1963; Natches in U9ak and Kohocton in U9ak-1, both on 8/23/1963; Handicap in U9ba on 3/12/1964; Hook in U9bc on 4/14/1964; Campos in U9cp on 2/13/1978; Niza in U9cr on 7/10/1981; and Galena (Yellow, Orange, and Green) in U9cv on $6 / 23 / 1992$.

Oconto collapsed to the surface 39 minutes 45 seconds after detonation. It formed a crater $11 \mathrm{~m}$ deep and $137 \mathrm{~m}$ in diameter. There were two vertical satellite holes and three vertical posttest holes associated with Oconto, all located within the collapse crater. U9ay \#1 was drilled to $282 \mathrm{~m}$; U9ay\#2 was drilled to $15 \mathrm{~m}$ and abandoned. PS 1 was abandoned at $314 \mathrm{~m}$ depth soon after drilling. PS 2, drilled to a depth of $312 \mathrm{~m}$, and PS 3, drilled to a depth of $314 \mathrm{~m}$, were surveyed, sampled, and capped. Oconto had an accidental release of radioactivity detected onsite only.

We have reviewed geology and test-related data, including information on the cavity and crater, and believe that complete collapse occurred quickly after detonation. The number of subsequent tests on Yucca Flat, and the entire NTS, gives us comfort that cavity collapse and crater formation should be complete. The ground surface above the U9ay site has not changed over time, so it seems reasonable to conclude that the current configuration is stable. We have evaluated crater stability produced from cavity collapse, and have not considered later erosion effects. We rely on NSTec and DOE/NNSA/NSO to make decisions concerning safety issues related to reentering the crater area. 


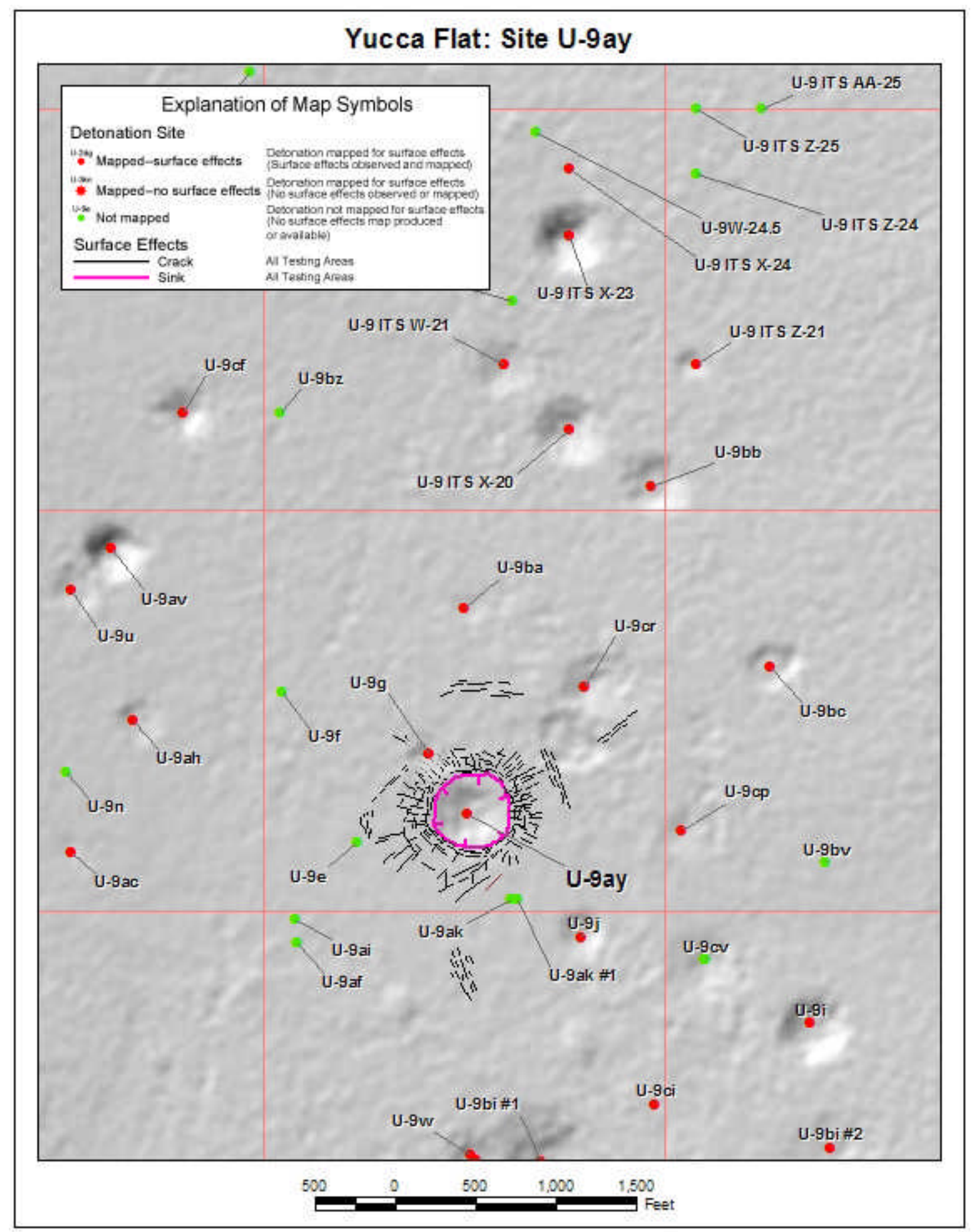

Figure 1. Surface effects map of hole U9ay (Grasso, 2003). 


\section{Hook \\ U9bc}

The LLNL sponsored Hook test was detonated in hole U9bc on 4/14/1964. Hook had an announced yield of "low" (which equates to $<20 \mathrm{kt}$ ) (DOE/NV-209-Rev 15). It was detonated in tuff at a working point of $204 \mathrm{~m}$ below the surface. U9bc is located in eastern central Area 9, between the Yucca Fault to the west and the Area 9 Fault to the east. U9bc is located just south of the Area 9 ITS region. Figure 2 shows nearby holes and surface effects. Nearby tests include: Oconto in U9ay on 1/23/1964; Bunker in U9bb on 2/13/1964; Handicap in U9ba on 3/12/1964; Switch in U9bv on 6/22/1967; Campos in U9cp on 2/13/1978; and Niza in U9cr on 7/10/198.

Hook collapsed to the surface 15 minutes 45 seconds after detonation. It formed a crater $7 \mathrm{~m}$ deep and $90 \mathrm{~m}$ in diameter. There was a vertical satellite hole and two vertical posttest holes associated with Hook, all located within the collapse crater. U9bc \#1 $246 \mathrm{~m}$. PS 1, drilled to a depth of $238 \mathrm{~m}$, and PS 2, drilled to a depth of $246 \mathrm{~m}$, were logged, sampled, and capped. Hook had an accidental release of radioactivity detected onsite only.

We have reviewed geology and test-related data, including information on the cavity and crater, and believe that complete collapse occurred quickly after detonation. The number of subsequent tests on Yucca Flat, and the entire NTS, gives us comfort that cavity collapse and crater formation should be complete. The ground surface above the U9bc site has not changed over time, so it seems reasonable to conclude that the current configuration is stable. We have evaluated crater stability produced from cavity collapse, and have not considered later erosion effects. We rely on NSTec and $\mathrm{DOE} / \mathrm{NNSA} / \mathrm{NSO}$ to make decisions concerning safety issues related to reentering the crater area. 


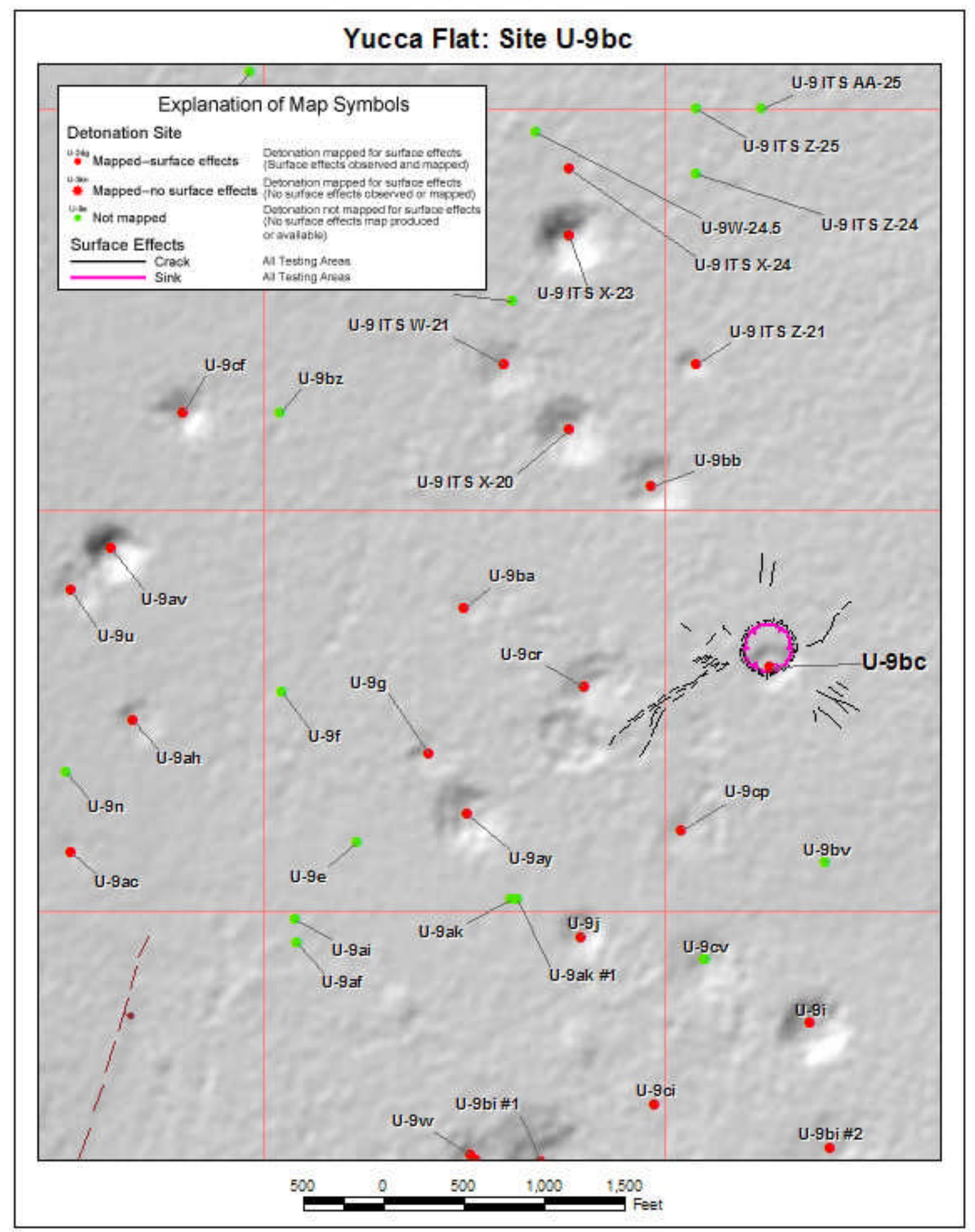

Figure 2. Surface effects map of hole U9bc (Grasso, 2003). 


\section{Links \\ U9bf}

The LLNL sponsored Links test was detonated in hole U9bf on 7/23/1964. Links had an announced yield of "low" (which equates to $<20 \mathrm{kt})(\mathrm{DOE} / \mathrm{NV}-209-\mathrm{Rev} 15)$. It was detonated in alluvium at a working point of $120 \mathrm{~m}$ below the surface. U9bf is located in south central Area 9 between the Yucca Fault to the west and the Area 9 Fault to the east. Figure 3 shows nearby holes and surface effects. Nearby tests include: Allegheny in U9x on 9/29/1962; Chenille in U9bg on 4/22/1965; Izzer in U9bp on 7/16/1965; Elkhart in U9bs on 9/17/1965; Templar in U9bt on 3/24/1966; and Cathay in U9ch on $10 / 8 / 1971$.

There were three vertical posttest holes associated with Links, all within the collapse crater. Preposttest hole PPS2A was abandoned at $21 \mathrm{~m}$. PS $1 \mathrm{~V}$, drilled to a depth of $151 \mathrm{~m}$, and PS $2 \mathrm{~V}$, drilled to a depth of $97.5 \mathrm{~m}$, were logged, sampled, and capped. Links had an accidental release of radioactivity detected onsite only.

We have reviewed geology and test-related data for Links, including information on the cavity. We know that:

- Links did not collapse to the surface. If we assumed a maximum yield of $20 \mathrm{kt}$ for the announced yield, collapse to the surface would have occurred based on scaled depth of burial (SDOB) guidelines used today. At that maximum yield the SDOB would be about $49 \mathrm{~m} / \mathrm{kt}^{1 / 3}$. Generally speaking, tests with smaller SDOBs are more likely to collapse to the surface after detonation.

- Test-specific geophone data indicate a subsurface collapse may have occurred within about 17 seconds of detonation. We could find no information on subsurface collapse time or height.

- With the working point in alluvium and a small SDOB, it is hard to predict where subsurface collapse might terminate.

- Links in U9bf is located in a well-used testing area and surrounded by many tests, some of them relatively large. The ground surface at the U9bf site has not changed over the 28 years of subsequent ground motion caused by underground testing.

We have reviewed geology and test-related data, including information on the cavity and subsequent subsurface collapse. We don't know if the subsurface collapse has changed over time, nor can we preclude that small, additional collapses have or have not occurred. Ground motion from many subsequent tests gives credibility that collapse is complete and permits us to conclude that the current configuration may be stable. However, LLNL has less confidence than normal in making this statement. We rely on NSTec and DOE/NNSA/NSO to make decisions concerning safety issues related to reentering potential crater areas. 


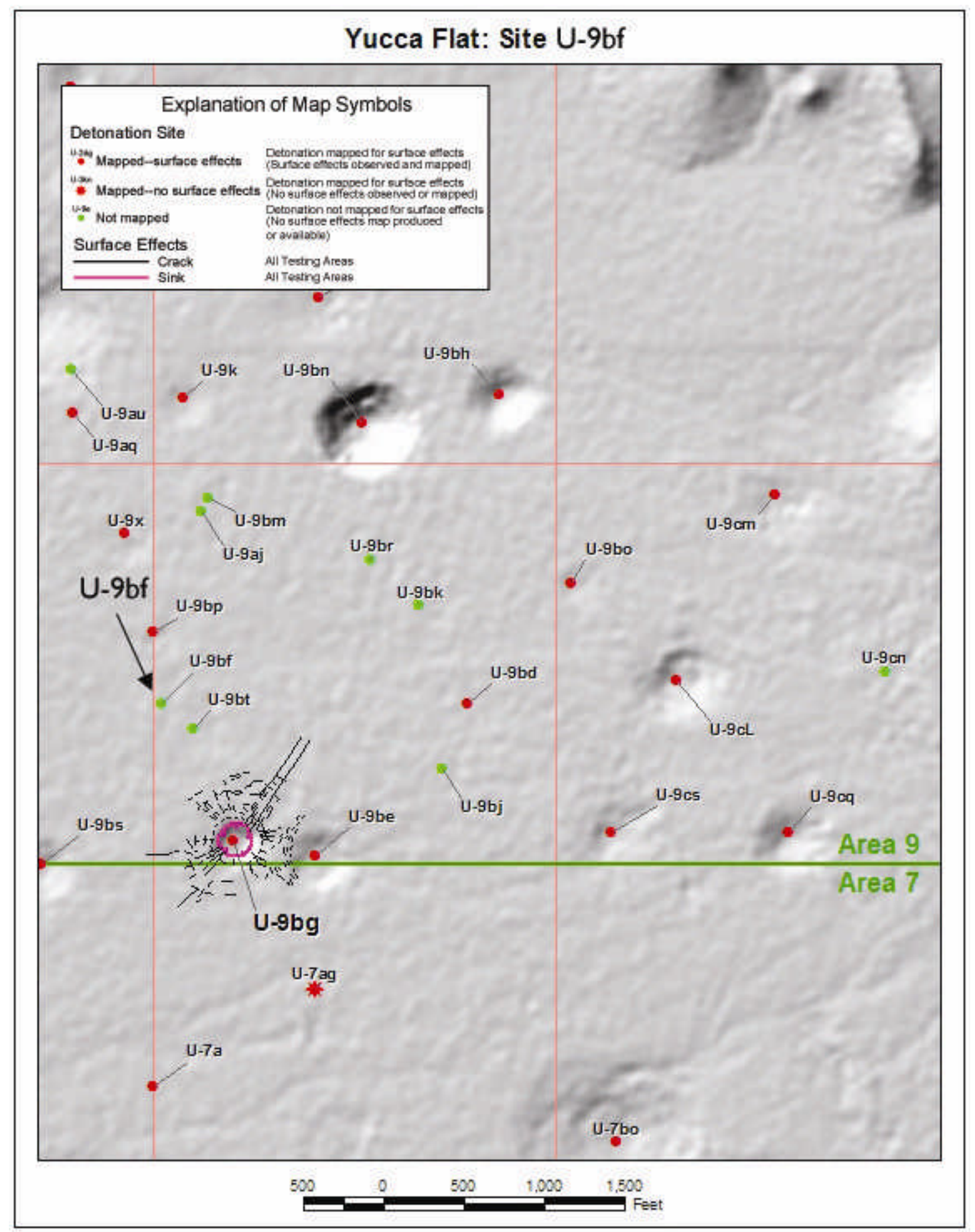

Figure 3. Surface effects map of hole U9bf (Grasso, 2003). 


\section{Brazos \\ U9d}

The LLNL sponsored Brazos test was detonated in hole U9d on 3/8/1962. Brazos had an announced yield of $8.4 \mathrm{kt}$ (DOE/NV-209-Rev 15). It was detonated in alluvium at a working point of $256 \mathrm{~m}$ below the surface. U9d is located in western Area 9, just east of the Yucca Fault. Figure 4 shows nearby holes and surface effects. Nearby tests include: Eel in U9m on 5/19/1962; White in U9b on 5/25/1962; Sacramento in U9v on 6/30/1962; Roanoke in U9q on 10/12/1962; Kaweah in U9ab on 2/21/1963; Greys in U9ax on 11/22/1963; Knox in U2at on 2/21/1968; Rack in U9ap on 8/15/1968; Ildrim in U2au on 7/16/1969; and Branco and Branco-Herkimer, both in U2ew on 9/21/1983.

Brazos collapsed to the surface 38 minutes after detonation. It formed a crater $9 \mathrm{~m}$ deep and $107 \mathrm{~m}$ in diameter. There were three holes associated with Brazos. Two vertical holes were collared within the collapse crater: a satellite hole for gas sampling (\#1 R/C), located about $6 \mathrm{~m}$ from the emplacement hole, and PS 1, drilled to a depth of $290 \mathrm{~m}$. PS 2 was a slant hole drilled to a depth of $310 \mathrm{~m}$. (We noted some confusion concerning hole names on various records for these three holes). Brazos had an accidental release of radioactivity detected onsite only.

We have reviewed geology and test-related data, including information on the cavity and crater, and believe that complete collapse occurred quickly after detonation. The number of subsequent tests on Yucca Flat, and the entire NTS, gives us comfort that cavity collapse and crater formation should be complete. The ground surface above the U9d site has not changed over time, so it seems reasonable to conclude that the current configuration is stable. We have evaluated crater stability produced from cavity collapse, and have not considered later erosion effects. We rely on NSTec and DOE/NNSA/NSO to make decisions concerning safety issues related to reentering the crater area. 


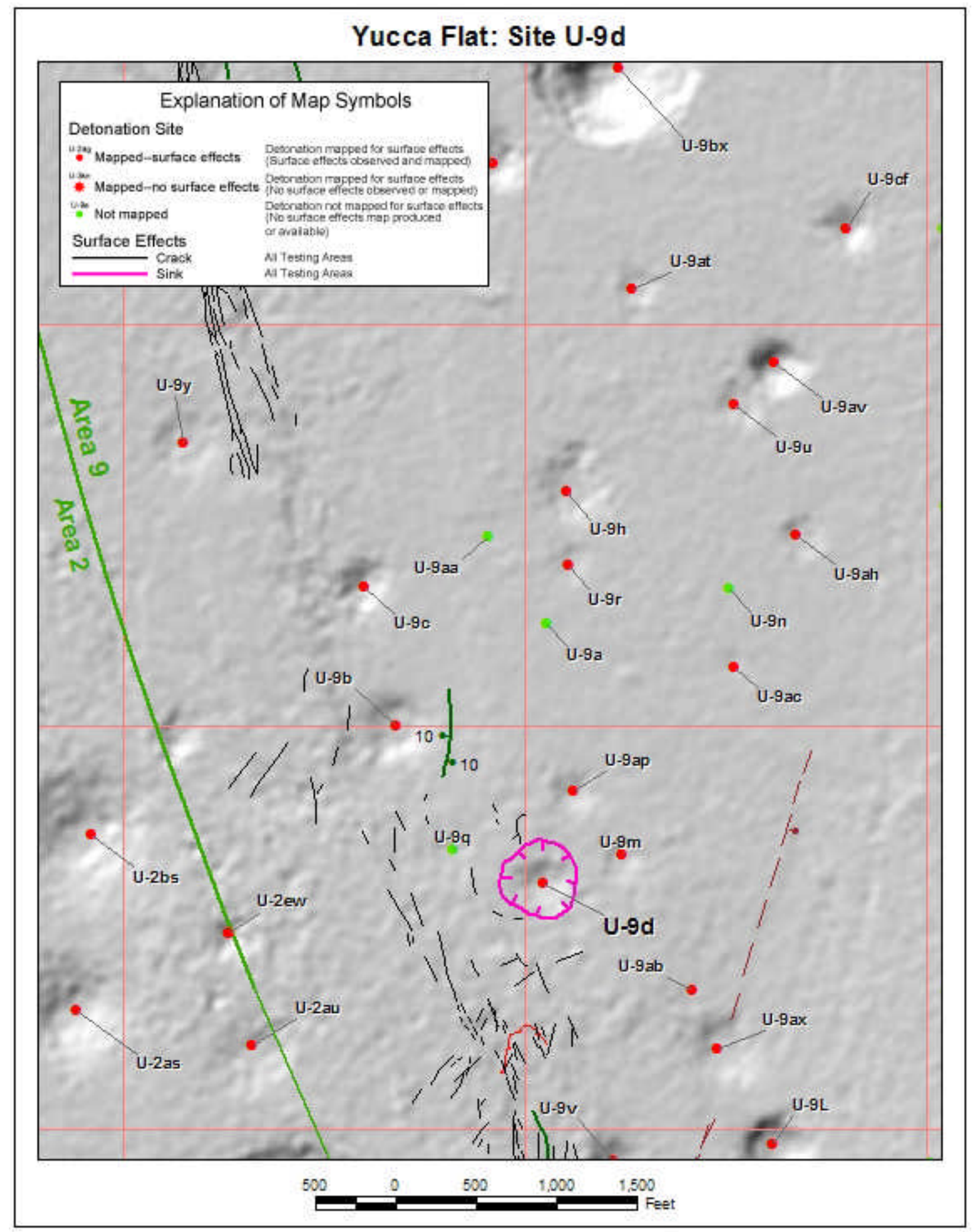

Figure 4. Surface effects map of hole U9d (Grasso, 2003). 


\section{Anacostia}

U9i

The LLNL sponsored Anacostia test was detonated in hole U9i on 11/27/1962. Anacostia, a Plowshare test, had an announced yield of $5.2 \mathrm{kt}$ (DOE/NV-209-Rev 15). It was detonated in tuff at a working point of $226 \mathrm{~m}$ below the surface. U9i is located in eastern Area 9 between the Yucca Fault to the west and the Area 9 Fault to the east. It is located south of the Area 9 ITS region. Figure 5 shows nearby holes and surface effects. Nearby tests include: Dead in U9k on 4/21/1962;

Kootanai in U9w and Paisano in U9w-1, both on 4/24/1963; Bogey in U9au on 4/17/1964; Tweed in U9bn on 5/21/1965; Switch in U9bv on 6/22/1967; Terrine White in U9bi-1 and Terrine Yellow in U9bi-2, both on 12/18/1969; Arsenate in U9ci on 11/9/1972; and Galena (Yellow, Orange, and Green) in U9cv on 6/23/1992.

Anacostia collapsed to the surface in 23 minutes 12 seconds after detonation. It formed a crater $19 \mathrm{~m}$ deep and $140 \mathrm{~m}$ in diameter. There were three vertical holes associated with Anacostia, all within the collapse crater: a satellite hole for gas sampling (\#1 R/C), drilled to a depth of $231 \mathrm{~m}$; PS1, drilled to a depth of $274 \mathrm{~m}$, and PS 2, drilled to a depth of $260 \mathrm{~m}$. Both posttest holes were surveyed and sampled. Anacostia had an accidental release of radioactivity detected onsite only.

We have reviewed geology and test-related data, including information on the cavity and crater, and believe that complete collapse occurred quickly after detonation. The number of subsequent tests on Yucca Flat, and the entire NTS, gives us comfort that cavity collapse and crater formation should be complete. The ground surface above the U9i site has not changed over time, so it seems reasonable to conclude that the current configuration is stable. We have evaluated crater stability produced from cavity collapse, and have not considered later erosion effects. We rely on NSTec and DOE/NNSA/NSO to make decisions concerning safety issues related to reentering the crater area. 


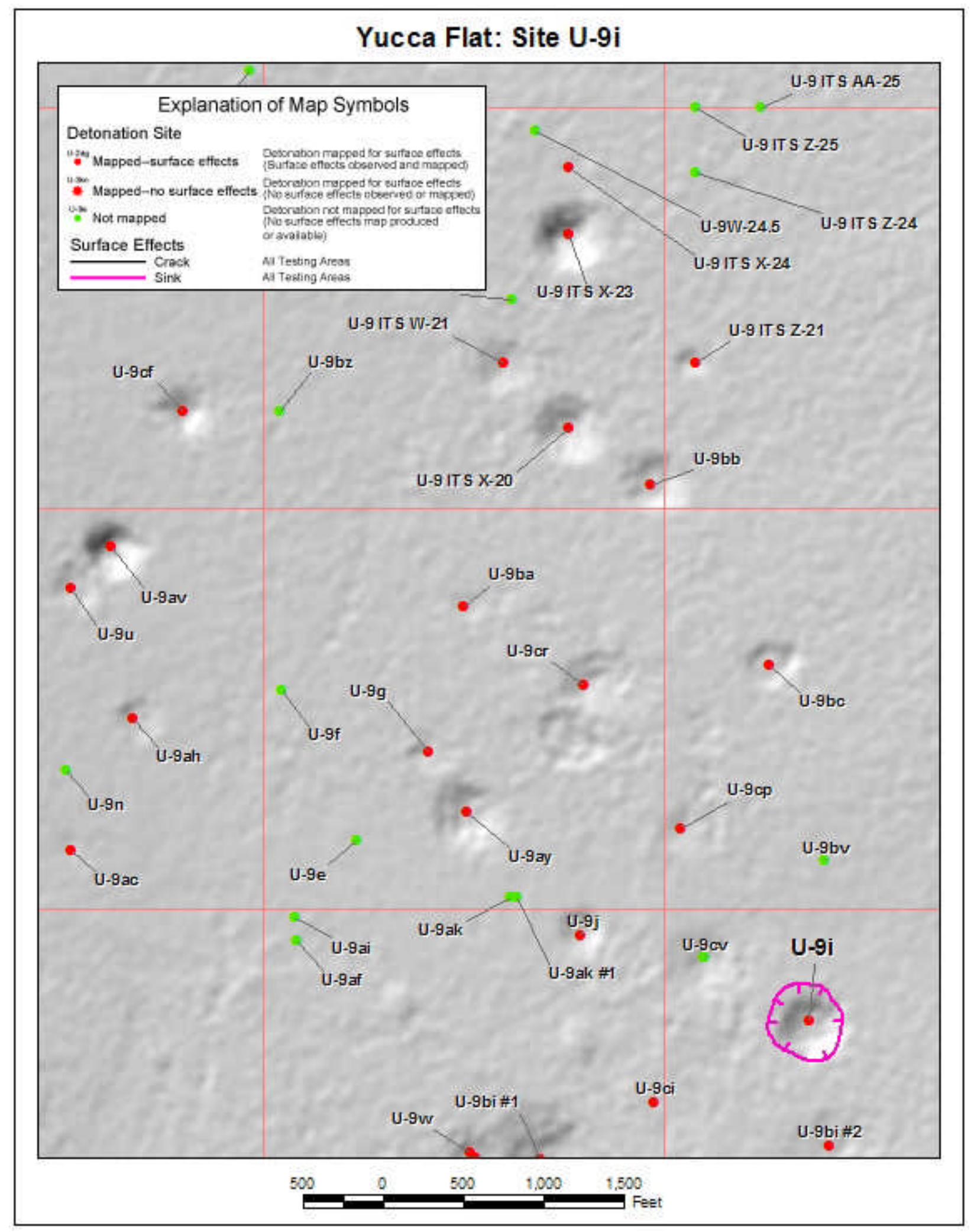

Figure 5. Surface effects map of hole U9i (Grasso, 2003). 


\section{Eel \\ U9m}

The LLNL sponsored Eel test was detonated in hole U9m on 5/19/1962. Eel had an announced yield of $4.5 \mathrm{kt}$ (DOE/NV-209_-Rev 15). It was detonated in alluvium at a working point of $217 \mathrm{~m}$ below the surface. U9m is located in western Area 9 just east of the Yucca Fault. Figure 6 shows nearby holes and surface effects. Nearby tests include: Brazos in U9d on 3/8/1962; White in U9b on 5/25/1962; Roanoke in U9q on 10/12/1962; Kaweah in U9ab on 2/21/1963; and Rack in U9ap on $8 / 15 / 1968$.

Eel collapsed to the surface 21 minutes after detonation. It formed a crater $4 \mathrm{~m}$ deep and $76 \mathrm{~m}$ in diameter. There were five holes associated with Eel, four collared within the collapse crater. PS 1 and three satellite radiochemistry holes $(\# 1 \mathrm{R} / \mathrm{C}, \# 2 \mathrm{R} / \mathrm{C}$, and \#3 R/C) are within the collapse crater. PS 2 was a slant hole collared outside the collapse crater. Eel had an accidental release of radioactivity detected offsite.

We have reviewed geology and test-related data, including information on the cavity and crater, and believe that complete collapse occurred quickly after detonation. The number of subsequent tests on Yucca Flat, and the entire NTS, gives us comfort that cavity collapse and crater formation should be complete. The ground surface above the U9m site has not changed over time, so it seems reasonable to conclude that the current configuration is stable. We have evaluated crater stability produced from cavity collapse, and have not considered later erosion effects. We rely on NSTec and $\mathrm{DOE} / \mathrm{NNSA} / \mathrm{NSO}$ to make decisions concerning safety issues related to reentering the crater area. 


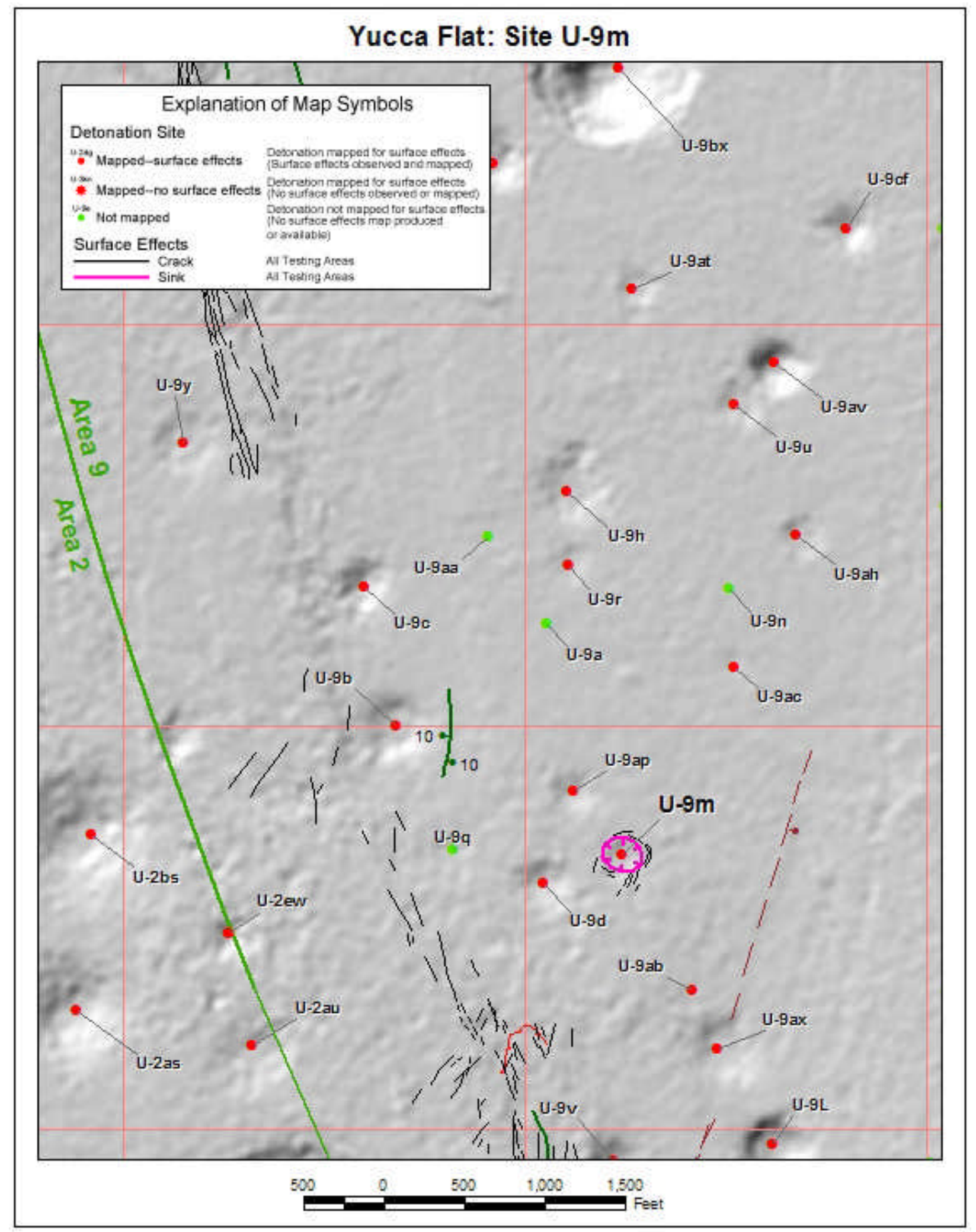

Figure 6. Surface effects map of hole U9m (Grasso, 2003). 


\section{Roanoke \\ U9q}

The LLNL sponsored Roanoke test was detonated in hole U9q on 10/12/1962. Roanoke had an announced yield of "low" (which equates to $<20 \mathrm{kt}$ ) (DOE/NV-209-Rev 15). It was detonated in alluvium at a working point of $176 \mathrm{~m}$ below the surface. U9q is located in western Area 9, just east of the Yucca Fault. Figure 7 shows nearby holes and surface effects. Nearby tests include: Brazos in U9d on 3/8/1962; Eel in U9m on 5/19/1962; White in U9b on 5/25/1962; Rack in U9ap on 8/15/1968; Ildrim in U2au on 7/16/1969; and Branco and Branco-Herkimer, both in U2ew on 9/21/1983.

Roanoke collapsed to the surface 15 minutes after detonation. It formed a crater $2 \mathrm{~m}$ deep and $24 \mathrm{~m}$ in diameter. There were three vertical posttest holes associated with Roanoke and all collared within the collapse crater: PS 1 was drilled to a depth of $46 \mathrm{~m}$ and then abandoned because of surface settling; PS 1S and PS 2, both drilled to a depth of $192 \mathrm{~m}$. PS 1S and PS 2 were surveyed and sampled. Roanoke had an accidental release of radioactivity that was detected onsite only.

We have reviewed geology and test-related data, including information on the cavity and crater, and believe that complete collapse occurred quickly after detonation. The number of subsequent tests on Yucca Flat, and the entire NTS, gives us comfort that cavity collapse and crater formation should be complete. The ground surface above the U9q site has not changed over time, so it seems reasonable to conclude that the current configuration is stable. We have evaluated crater stability produced from cavity collapse, and have not considered later erosion effects. We rely on NSTec and DOE/NNSA/NSO to make decisions concerning safety issues related to reentering the crater area. 


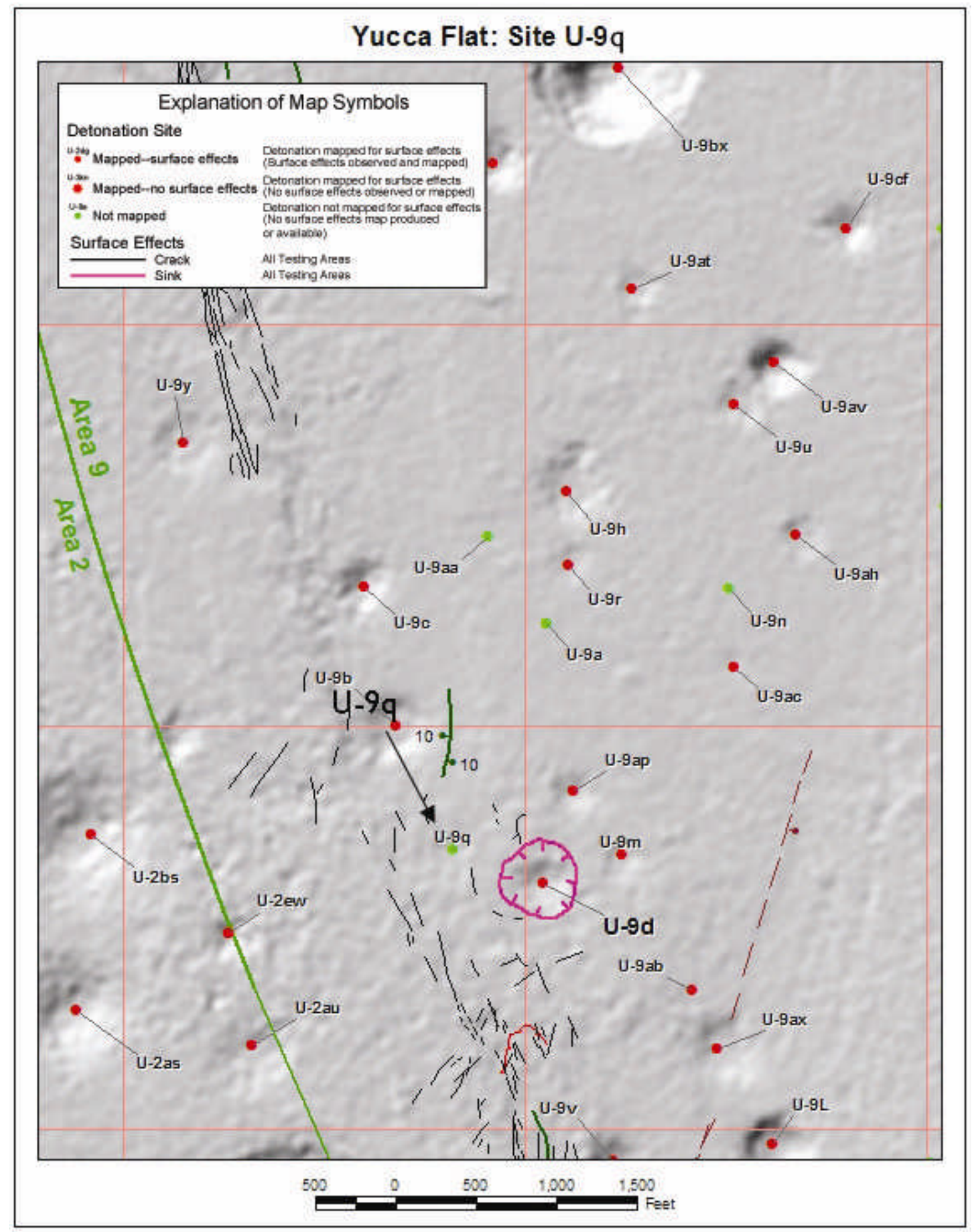

Figure 7. Surface effects map of hole U9q (Grasso, 2003). 


\section{Raritan \\ U9u}

The LLNL sponsored Raritan test was detonated in hole U9u on 9/6/1962. Raritan had an announced yield of "low" (which equates to $<20 \mathrm{kt}$ ) (DOE/NV-209-Rev 15). It was detonated in alluvium at a working point of $157 \mathrm{~m}$ below the surface. U9u is located in central Area 9, between the Yucca Fault to the west and the Area 9 Fault to the east. U9u is located in the southwest corner of the Area 9 ITS region. Figure 8 shows nearby holes and surface effects. Nearby tests include: Cimarron in U9h on 2/23/1962; Tioga in U9f on 10/18/1962; Mustang in U9at on 11/15/1963; and Eagle in U9av on12/12/1963.

Raritan collapsed to the surface 2 minutes after detonation. It formed a crater $7 \mathrm{~m}$ deep and $67 \mathrm{~m}$ in diameter. There were two vertical posttest holes associated with Raritan, both collared within the collapse crater: PS 1, drilled to a depth of $192 \mathrm{~m}$, and PS 2, drilled to a depth of $196 \mathrm{~m}$. Both holes were surveyed and sampled.

We have reviewed geology and test-related data, including information on the cavity and crater, and believe that complete collapse occurred quickly after detonation. The number of subsequent tests on Yucca Flat, and the entire NTS, gives us comfort that cavity collapse and crater formation should be complete. The ground surface above the U9u site has not changed over time, so it seems reasonable to conclude that the current configuration is stable. We have evaluated crater stability produced from cavity collapse, and have not considered later erosion effects. We rely on NSTec and $\mathrm{DOE} / \mathrm{NNSA} / \mathrm{NSO}$ to make decisions concerning safety issues related to reentering the crater area. 


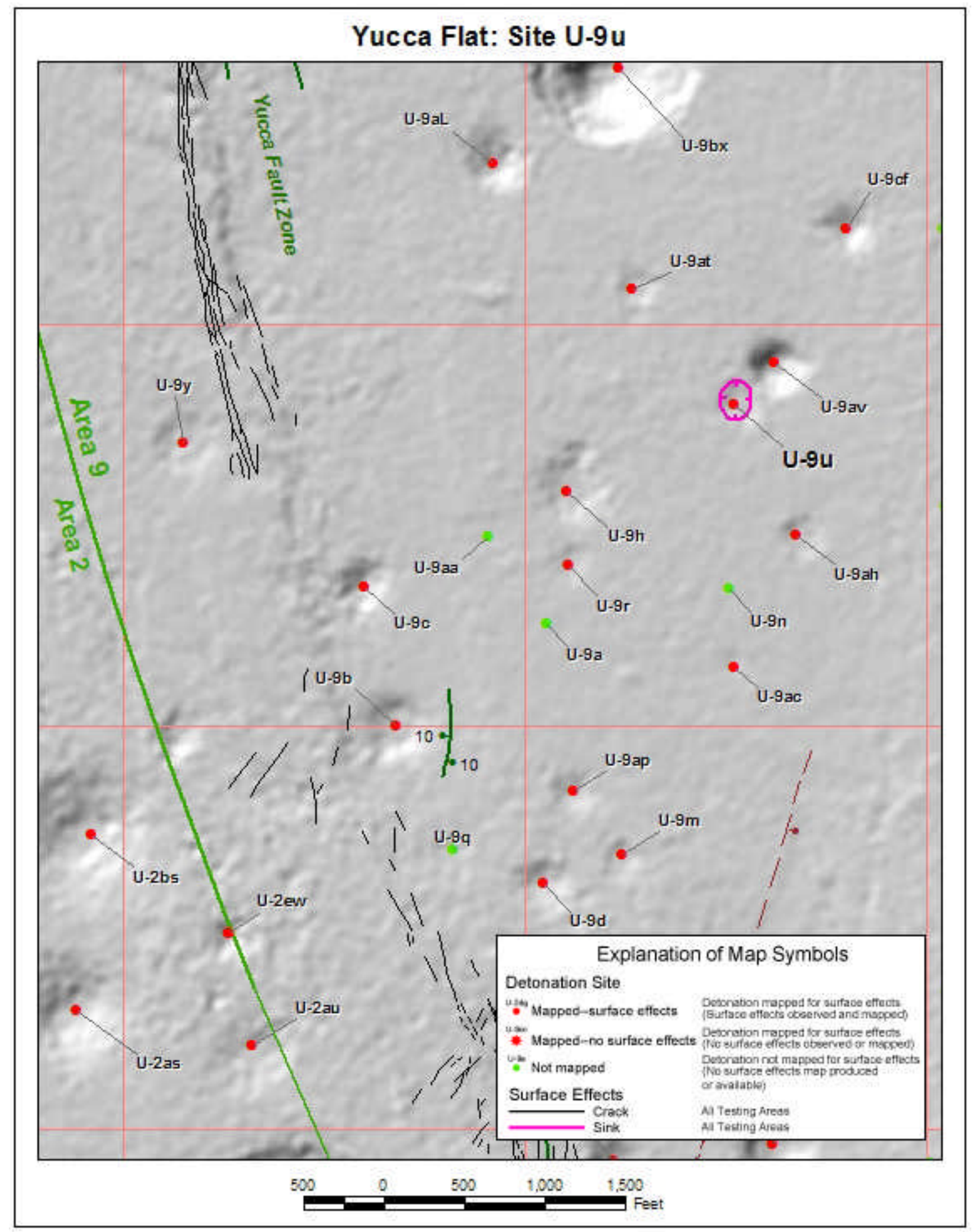

Figure 8. Surface effects map of hole U9u (Grasso, 2003). 


\section{Sacramento}

U9v

The LLNL sponsored Sacramento test was detonated in hole U9v on 6/30/1962. Sacramento had an announced yield of "low" (which equates to $<20 \mathrm{kt}$ ) (DOE/NV-209-Rev 15). It was detonated in alluvium at a working point of $149 \mathrm{~m}$ below the surface. U9v is located in south western Area 9, just east of the Yucca Fault. Figure 9 shows nearby holes and surface effects. Nearby tests include: Brazos in U9d on 3/8/1962; Passiac in U91 on 4/6/1962; Eel in U9m on 5/19/1962; Greys in U9ax on 11/22/1963; Crepe in U2q on 12/05/1964; Knox in U2at on 2/21/1968; Rack in U9ap on 8/15/1968; Ildrim in U2au on 7/16/1969; and Branco and Branco-Herkimer, both in U2ew on 9/21/1983.

Sacramento collapsed to the surface 5 minutes 30 seconds after detonation. It formed a crater $21 \mathrm{~m}$ deep and $110 \mathrm{~m}$ in diameter. There were two vertical posttest holes associated with Sacramento, both in the collapse crater: PS 1, drilled to a depth of $183 \mathrm{~m}$, and PS 2, drilled to a depth of $184 \mathrm{~m}$. Both holes were surveyed and sampled.

We have reviewed geology and test-related data, including information on the cavity and crater, and believe that complete collapse occurred quickly after detonation. The number of subsequent tests on Yucca Flat, and the entire NTS, gives us comfort that cavity collapse and crater formation should be complete. The ground surface above the U9v site has not changed over time, so it seems reasonable to conclude that the current configuration is stable. We have evaluated crater stability produced from cavity collapse, and have not considered later erosion effects. We rely on NSTec and DOE/NNSA/NSO to make decisions concerning safety issues related to reentering the crater area. 


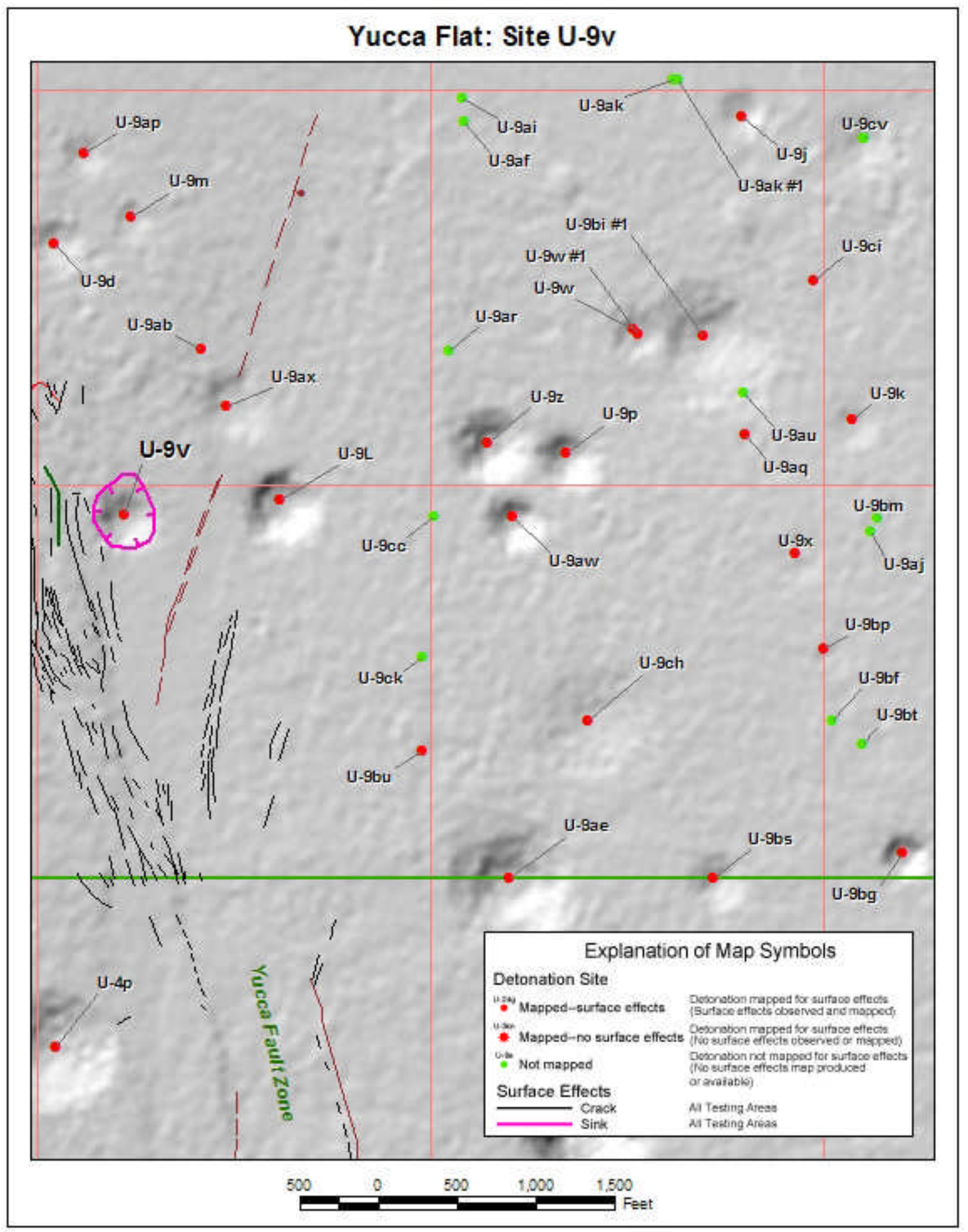

Figure 9. Surface effects map of hole U9v (Grasso, 2003). 


\section{Allegheny \\ U9x}

The LLNL sponsored Allegheny test was detonated in hole U9x on 9/29/1962. Allegheny had an announced yield of "low" (which equates to $<20 \mathrm{kt}$ ) (DOE/NV-209-Rev 15). It was detonated in alluvium at a working point of $210 \mathrm{~m}$ below the surface. U9x is located in south eastern Area 9, between the Yucca Fault to the west and the Area 9 Fault to the east. Figure 10 shows nearby holes and surface effects. Nearby tests include: Dead in U9k on 4/21/1962; Tornillo in U9aq on 10/11/1963; Garden in U9aj on 10/23/1964; Seersucker in U9bm on 2/19/1965; and Izzer in U9bp on $7 / 16 / 1965$.

Allegheny collapsed to the surface 13 minutes after detonation. It formed a crater $3 \mathrm{~m}$ deep and $88 \mathrm{~m}$ in diameter. There were three vertical holes associated with Allegheny, all within the collapse crater: a satellite hole for gas sampling (\#1 R/C), drilled to a depth of $262 \mathrm{~m}$; PS 1 - drilled to a depth of $275 \mathrm{~m}$; and PS 2, drilled to a depth of $268 \mathrm{~m}$. The posttest holes were surveyed and sampled. Allegheny had an accidental release of radioactivity that was detected onsite only.

We have reviewed geology and test-related data, including information on the cavity and crater, and believe that complete collapse occurred quickly after detonation. The number of subsequent tests on Yucca Flat, and the entire NTS, gives us comfort that cavity collapse and crater formation should be complete. The ground surface above the U9x site has not changed over time, so it seems reasonable to conclude that the current configuration is stable. We have evaluated crater stability produced from cavity collapse, and have not considered later erosion effects. We rely on NSTec and DOE/NNSA/NSO to make decisions concerning safety issues related to reentering the crater area. 


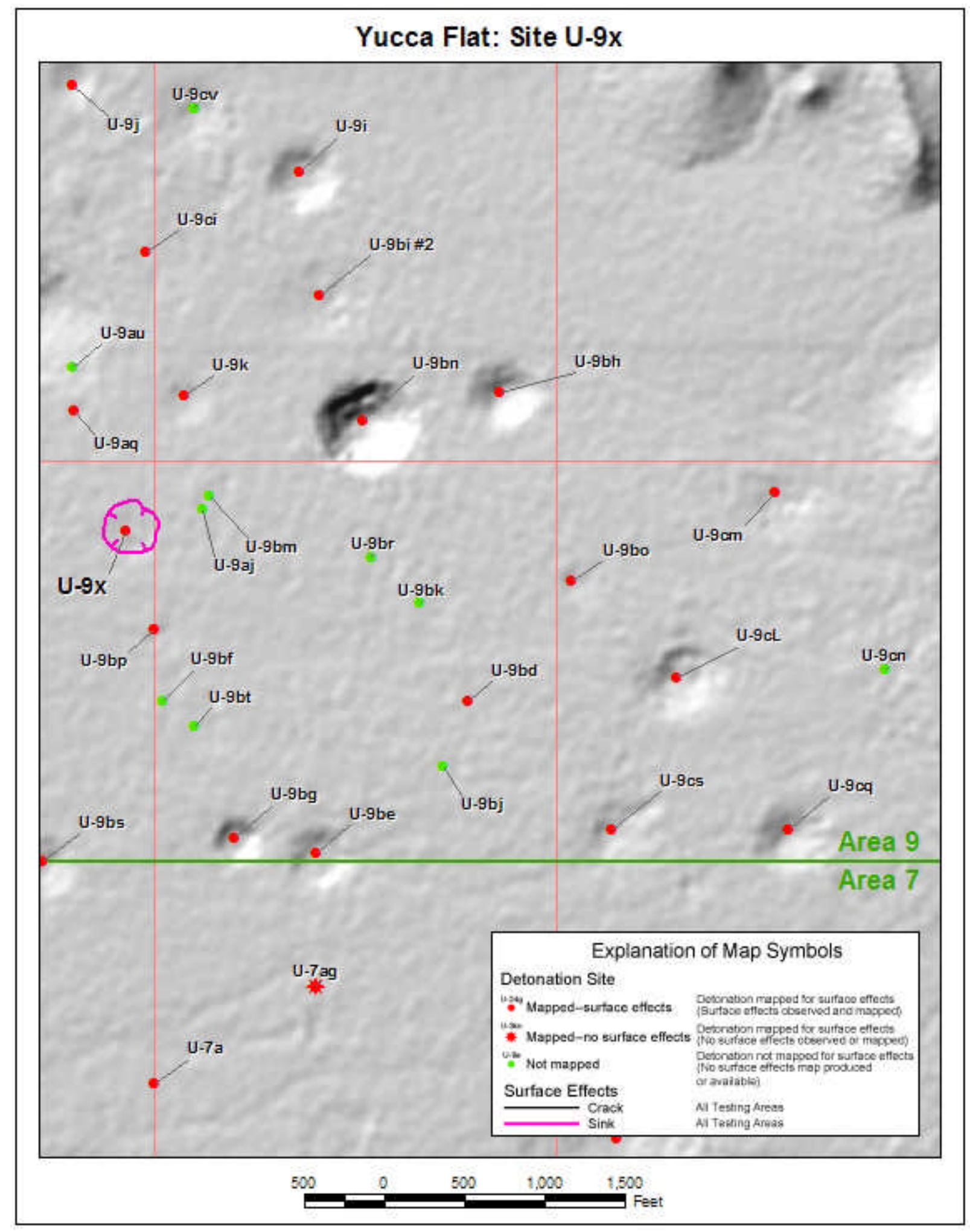

Figure 10. Surface effects map of hole U9x (Grasso, 2003). 


\section{Riola \\ U2eq}

The LLNL sponsored Riola test was detonated in U2eq on 9/25/1980. Riola had an announced yield of $1.07 \mathrm{kt}$ (DOE/NV-209-Rev 15). It was detonated in alluvium at a working point of $424 \mathrm{~m}$ below the surface. U2eq is located in southern Area 2, west of the Yucca Fault and east of the Carpetbag Fault. Figure 11 shows nearby holes and surface effects. Nearby tests include: simultaneous, separate hole tests Yannigan-Red in U2ay-1, Yannigan-White in U2ay-2, Yannigan-Blue in U2ay-3, all on 2/26/1970; simultaneous, separate hole tests Flask-Green in U2az-1, Flask-Yellow in U2az-2, Flask-Red in U2az-3, all on 5/26/1970; Nessel in U2ep on 8/29/1979; and Marsilly in U2el on 4/5/1977. Inventory emplacement holes U2ez (about $350 \mathrm{~m}$ to the southwest) and U2gi (about $1450 \mathrm{~m}$ to the northeast) are located nearby. A nearby hole U2ee was augered to $36 \mathrm{~m}$, backfilled, and abandoned.

Riola, which did not collapse to the surface, experienced an unusual collapse history, including an accidental release of radioactivity detected offsite. A number of operations were conducted to understand the release.

Geophones show that a stemming fall occurred from about 3.5-7.5 hours after detonation. Subsequent loss of stemming occurred until about 11 hours after detonation, when a release of radioactivity occurred. Some additional stemming material fell into the hole until about 11.5 hours after detonation. Radioactive gas penetrated to the surface through cracks between the surface conductor and surrounding grout pad, through cracks in the grout pad, and through a crack adjacent to the pad around the mousehole. Downhole photography showed about $46 \mathrm{~m}$ of drill hole enlarged up to two times original diameter above and below the stemming platform. Studies concluded that the both CTE plug (stemming platform) and the borehole failed. Several reports describe these studies, including "Riola Release Report" by E.C. Woodward, 1983, UCRL-53437. Note that heavy equipment was used near SGZ for these studies very soon after the radioactivity release. Downhole photographs show that the top of the chimney is at $346 \mathrm{~m}$ depth.

There were nine posttest holes associated with Riola: PS 1A, PS 1AA, and PS 1AB (three typical holes for posttest sampling), PPS 2A (abandoned), PS 3A, PS 3AA, PS 1D, PS 1DA, and PS 4A (drilled for downhole photography to understand the history of the radioactivity release).

We have reviewed geology, test-related, and posttest studies data, including information on the cavity, crater, and radioactivity release. The attention applied to data interpretation leaves us feeling comfortable we understand subsurface collapse history and release. It is clear the drill hole is enlarged and open for about $46 \mathrm{~m}$ near the original location of the stemming platform (centered roughly about $210 \mathrm{~m}$ ). Heavy equipment drove over the surface during these studies and no further stemming falls or collapse was detected. Several tests have occurred in this vicinity after Riola (specifically Panamint on 5/21/1986 and Schellbourne on 5/13/1988), causing local ground motion. The number of subsequent tests on Yucca Flat, and the entire NTS, gives us comfort that cavity collapse should be complete. The ground surface above the U2eq site has not changed over time, so it seems reasonable to conclude that the current configuration is stable. We have not considered later erosion effects. However, LLNL has less confidence than normal in making this statement. We rely 
on NSTec and DOE/NNSA/NSO to make decisions concerning safety issues related to reentering the crater area. 


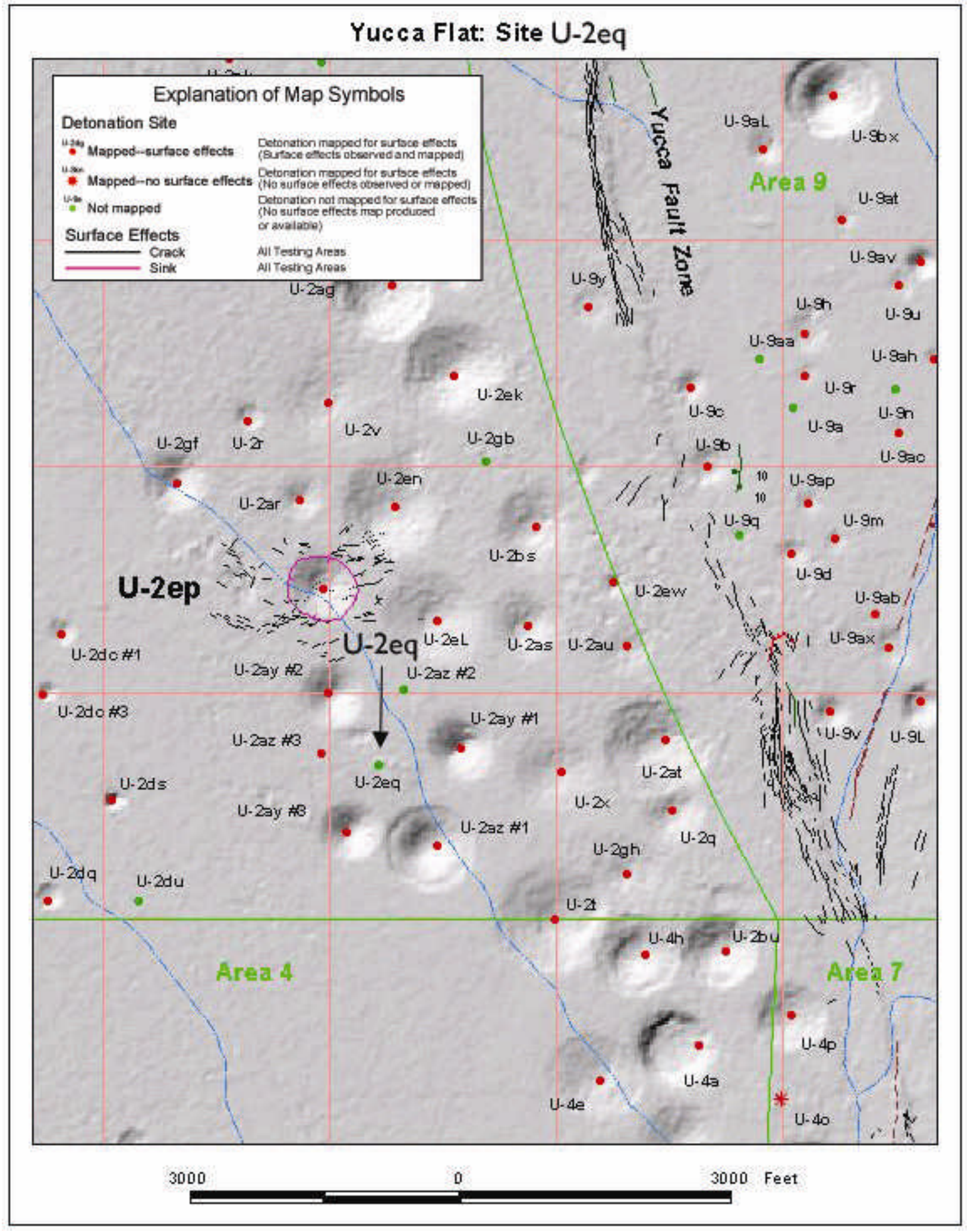

Figure 11. Surface effects map of hole U2eq (Grasso, 2003). 


\section{Mississippi \\ U9ad}

The LLNL sponsored Mississippi test was detonated in U9ad on 10/5/1962. Mississippi had an announced yield of $115 \mathrm{kt}$ (DOE/NV-209-Rev 15). It was detonated in tuff at a working point of $494 \mathrm{~m}$ below the surface. U9ad is located in central Area 9, between the Yucca Fault to the west and the Area 9 ITS region and Area 9 Fault to the east. Figure 12 shows nearby holes and surface effects. Nearby tests include: simultaneous, same hole tests Gruyere and Gruyere-Gradino in U9cg on 8/16/1977, Clymer in U9ce on 3/12/1966, Fore in U9ao on 1/16/1964, Noggin in U9bx on 9/6/1968, and Ajax in U9al on 11/11/1966.

Mississippi collapsed to the surface 67 minutes 30 seconds after detonation. It formed a crater $38 \mathrm{~m}$ deep and $291 \mathrm{~m}$ in diameter. There were two vertical posttest holes associated with Mississippi, both located within the collapse crater: PS 1, drilled to a depth of $536 \mathrm{~m}$, and PS 2, drilled to a depth of $579 \mathrm{~m}$. Both posttest holes were surveyed and sampled.

We have reviewed geology and test-related data, including information on the cavity and crater, and believe that complete collapse occurred soon after detonation. The number of subsequent tests on Yucca Flat, and the entire NTS, gives us comfort that cavity collapse and crater formation should be complete. The ground surface above the U9ad site has not changed over time, so it seems reasonable to conclude that the current configuration is stable. We have evaluated crater stability produced from cavity collapse, and have not considered later erosion effects. We rely on NSTec and $\mathrm{DOE} / \mathrm{NNSA} / \mathrm{NSO}$ to make decisions concerning safety issues related to reentering the crater area. 


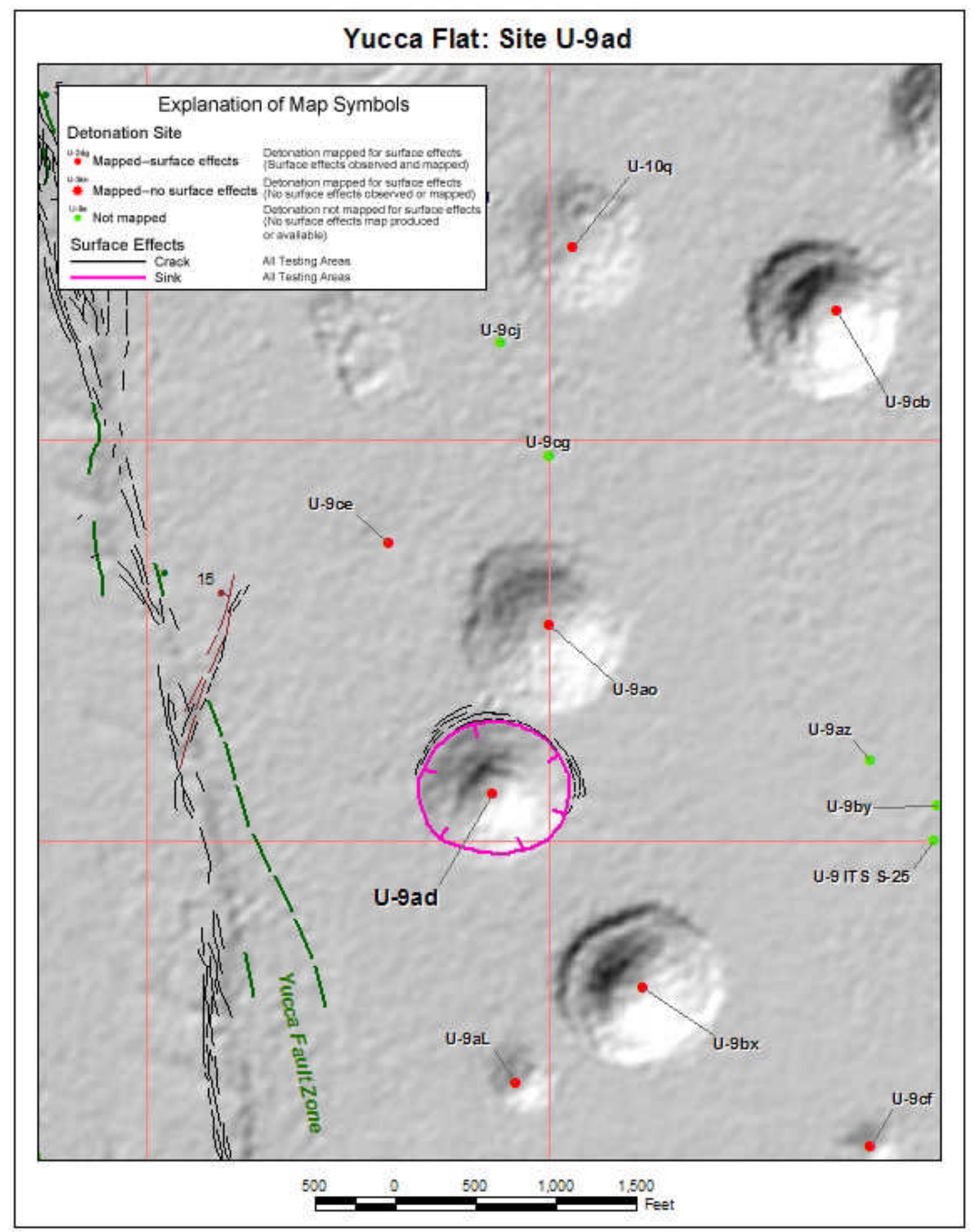

Figure 12. Surface effects map of hole U9ad (Grasso, 2003). 


\section{U9ag}

U9ag, in central Area 9 between the Yucca Fault to the west and the Area 9 ITS region and Area 9 Fault to the east, is in a localized region of Area 9 that has been frequently used for underground nuclear testing (see Figure 13 for nearby holes and surface effects). Numerous holes were drilled here between 1962 and 1972, and tests were detonated in many of them between 1962 and 1964. U9ag is a fairly shallow cased hole ( $1.83 \mathrm{~m}$ casing was set at $63 \mathrm{~m}$ in a $66 \mathrm{~m}$ total depth hole) drilled in 1964. For some reason it was not used as an emplacement hole (we could not find information on this topic). The dominant surface feature in this locality is the collapse crater from Terrine-White in U9bi-1, which was detonated on 12/18/1970. U9ag now is located on the edge of this collapse crater, as are Kootani (U9w), Paisano (U9w-1) and Bogey (U9au). Kootani and Paisano, simultaneous tests in separate holes, were detonated on 4/24/1963 and collapsed to the surface. Bogey was detonated on 4/17/1964 and did not collapse to the surface. U9bi-1 was drilled in 1969, after the execution of numerous tests in this locality. The subsequent Terrine-White collapse crater enveloped, or at least impacted, the boreholes, cavity, and chimney regions of U9w, U9w-1, U9au, and U9ag.

U9ag has three holes associated with it: an instrument hole and two pre-posttest holes. Instrument hole U9ag \#1, a cased hole with total depth of $76 \mathrm{~m}$, is a vertical hole within $9 \mathrm{~m}$ of U9ag. Two preposttest holes are also located nearby - PPS \#3 (drilled to $12 \mathrm{~m}$, cased to $12 \mathrm{~m}$, and abandoned) and PPS \#4 (drilled to $15 \mathrm{~m}$ with no casing and abandoned).

In order to evaluate the stability of U9ag, we evaluated the collapse history of closely located Bogey in U9au and subsequent Terrine-White in U9bi-1. The LLNL sponsored Bogey test was detonated on 4/17/1964. It had an announced yield of $<20 \mathrm{kt}$ (DOE/NV-209-Rev 15), and was detonated in alluvium at a working point of $119 \mathrm{~m}$ below the surface. Bogey did not collapse to the surface. The height to the top of the chimney is unknown. The LLNL sponsored Terrine-White test was detonated in U9bi-1 on 12/18/19692. Terrine-White was a simultaneous, separate hole test detonated along with Terrine-Yellow in U9bi-2 (the emplacement holes are about $550 \mathrm{~m}$ apart). Each Terrine test had an announced yield of 20-200 kt (DOE/NV209-REV 15). Terrine-White was detonated in tuff at a working point of $457 \mathrm{~m}$ below the surface. Terrine-White collapsed to the surface 7 hours and 13 minutes after detonation. It formed a crater $17 \mathrm{~m}$ deep and $256 \mathrm{~m}$ in diameter. Bogey was detonated after U9ag was drilled, and Terrine-White, a relatively large test, collapsed to the surface, enveloping U9ag and U9au. It is probable that ground motion from tests detonated after U9ag was drilled, in particularly these two nearby tests, have shaken the ground significantly and the current configuration is stable.

To assist in understanding the surface stability for U9ag we have reviewed geology and test-related data for U9au and U9bi-1, including information on cavity and crater formation. The number of tests near U9ag, the subsequent envelopment of U9ag by the U9bi-1 surface collapse crater, and the large number of subsequent tests on Yucca Flat and the entire NTS gives us comfort that cavity collapse and crater formation should be complete at the U9ag site. The ground surface near U9bi-1 and U9ag sites has not changed over time, so it seems reasonable to conclude that the current configuration is stable. However, LLNL has less confidence than normal in making this statement. We have evaluated crater stability produced from cavity collapse, and have not considered later 
erosion effects. We rely on NSTec and DOE/NNSA/NSO to make decisions concerning safety issues related to reentering the crater area. 


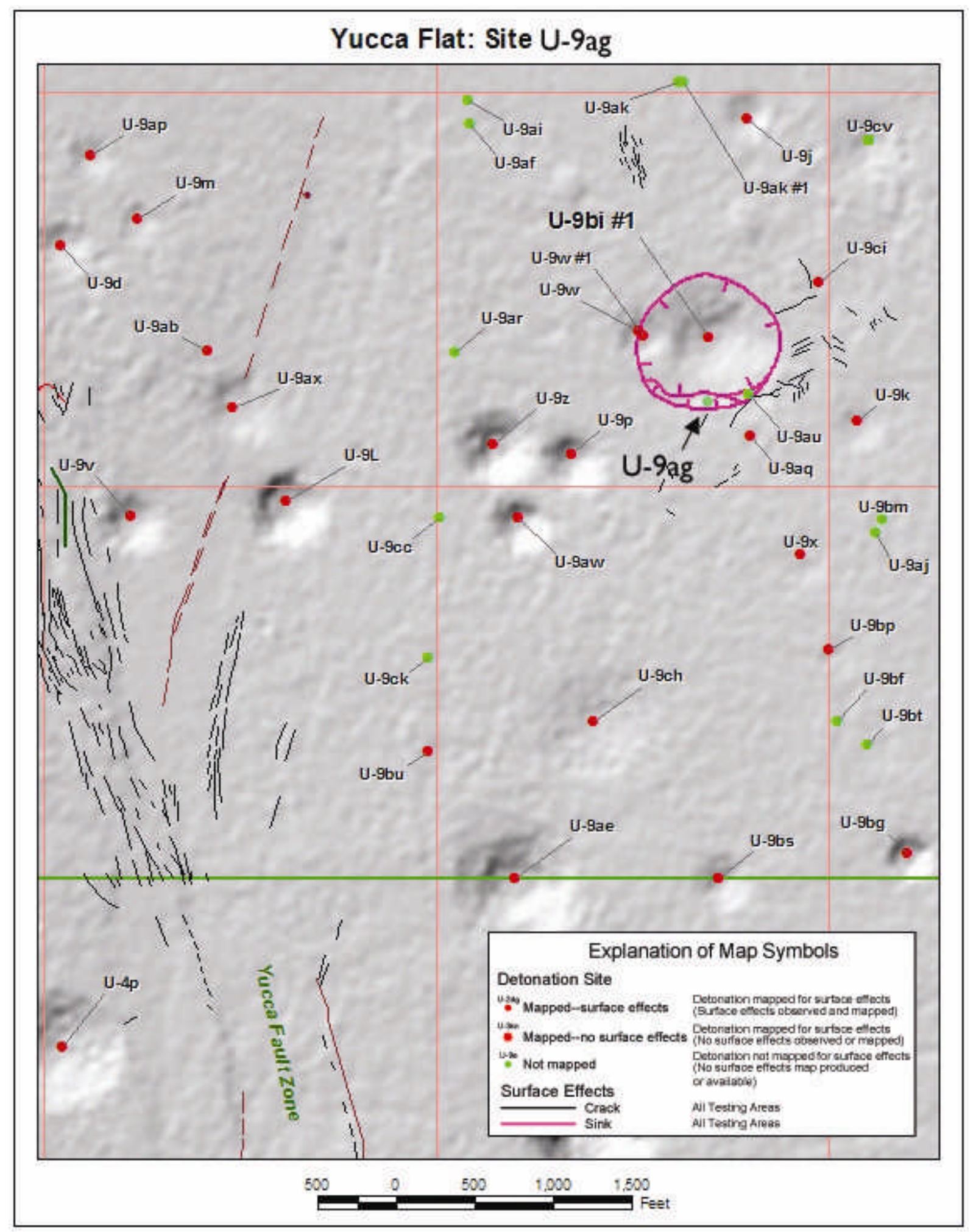

Figure 13. Surface effects map of hole U9ag (Grasso, 2003). 


\section{Fore \\ U9ao}

The LLNL sponsored Fore test was detonated in U9ao on 1/16/1964. Fore had an announced yield of 20 to $200 \mathrm{kt}$ (DOE/NV-209-Rev 15). It was detonated in vitric tuff at a working point of $491 \mathrm{~m}$ below the surface. U9ao is located in western Area 9, east of the Yucca Fault and west of the Area 9 ITS region. Figure 14 shows nearby holes and surface effects. Nearby tests include: Cup in U9cb on 3/26/1965, simultaneous tests in the same hole Gruyere and Gruyere-Gradino in U9cg on 8/16/1977, Clymer in U9ce on 3/12/1966, Mississippi in U9ad on 10/5/1962, Noggin in U9bx on 9/6/1968, Stanley in U10q on 7/27/1967, Alumroot in U9cj on 2/14/1973, and Tinderbox in U9az on 11/22/1968.

Fore collapsed to the surface 128 minutes after detonation. It formed a crater $38 \mathrm{~m}$ deep and $317 \mathrm{~m}$ in diameter. There are three holes associated with Fore, all collared within the surface collapse crater: a satellite hole and two vertical posttest holes. U9ao \#1 was drilled to $510 \mathrm{~m}$ depth. PS 1, drilled to a depth of $560 \mathrm{~m}$, and PS 2, drilled to a depth of $573 \mathrm{~m}$, were surveyed and sampled.

We have reviewed geology and test-related data, including information on the cavity and crater, and believe that complete collapse occurred soon after detonation. The number of subsequent tests on Yucca Flat, and the entire NTS, gives us comfort that cavity collapse and crater formation should be complete. The ground surface above the U9ao site has not changed over time, so it seems reasonable to conclude that the current configuration is stable. We have evaluated crater stability produced from cavity collapse, and have not considered later erosion effects. We rely on NSTec and DOE/NNSA/NSO to make decisions concerning safety issues related to reentering the crater area. 


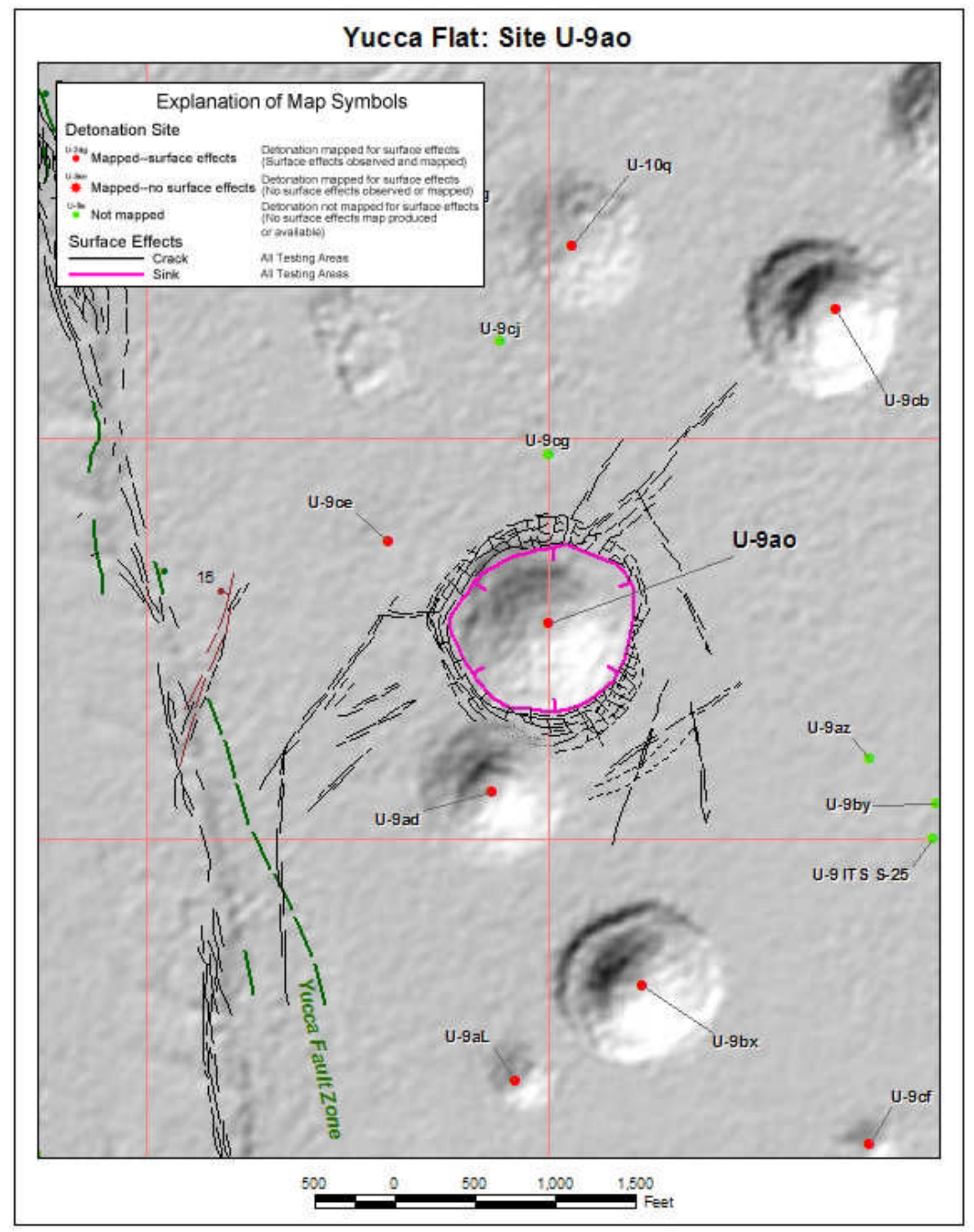

Figure 14. Surface effects map of hole U9ao (Grasso, 2003). 


\section{Greys \\ U9ax}

The LLNL sponsored Greys test was detonated in U9ax on 11/22/1963. Greys had an "intermediate" yield (which equates to 20-200 kt) (DOE/NV-209—Rev 15). It was detonated in alluvium at a working point of $305 \mathrm{~m}$ below the surface. U9ax is located in western Area 9 east of the Yucca Fault. Figure 15 shows nearby holes and surface effects. Nearby tests include: Mad in U9a on 12/13/1961, White in U9b on 5/25/1962, Stillwater in U9c on 2/8/1962, Brazos in U9d on 3/8/1962, Roanoke in U9q on 10/12/1962, Rack in U9ap on 8/15/1968, Eel in U9m on 5/19/1962, Kaweah in U9ab on 2/21/1963, Passaic in U91 on 4/6/1962, and Sacramento in U9v on 6/30/1962.

Greys collapsed to the surface in 52 minutes after detonation. It formed a crater $13 \mathrm{~m}$ deep and $122 \mathrm{~m}$ in diameter. There were two vertical holes associated with Greys, both within the collapse crater: PS 1, drilled to a depth of $335 \mathrm{~m}$, and PS 2, drilled to a depth of $356 \mathrm{~m}$. Both were surveyed and sampled.

We have reviewed geology and test-related data, including information on the cavity and crater, and believe that complete collapse occurred quickly after detonation. The number of subsequent tests on Yucca Flat, and the entire NTS, gives us comfort that cavity collapse and crater formation should be complete. The ground surface above the U9ax site has not changed over time, so it seems reasonable to conclude that the current configuration is stable. We have evaluated crater stability produced from cavity collapse, and have not considered later erosion effects. We rely on NSTec and DOE/NNSA/NSO to make decisions concerning safety issues related to reentering the crater area. 


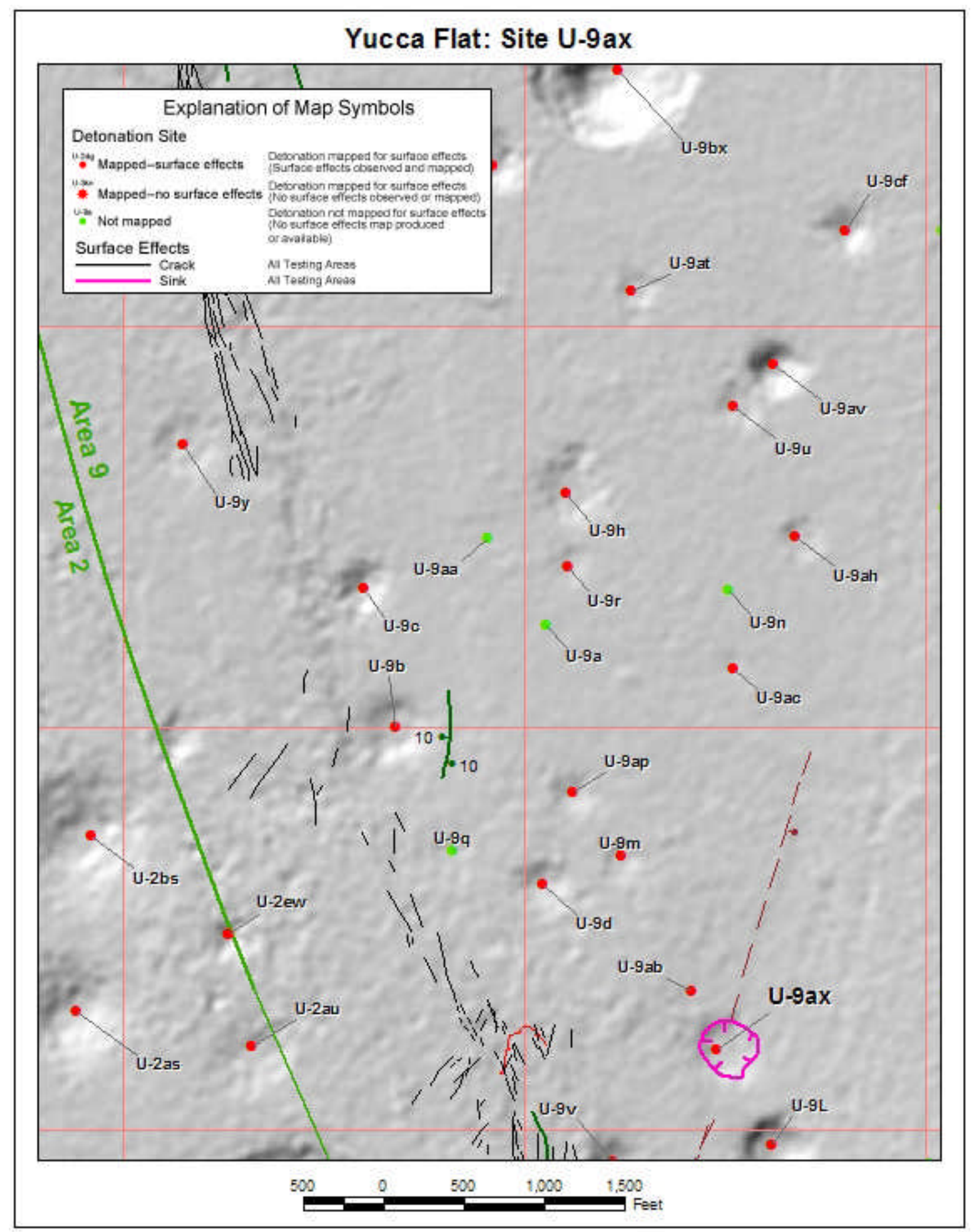

Figure 15. Surface effects map of hole U9ax (Grasso, 2003). 


\section{White \\ U9b}

The LLNL sponsored White test was detonated in U9b on 5/25/1962. White had an announced "low" yield (which equates to $<20 \mathrm{kt})(\mathrm{DOE} / \mathrm{NV}-209-\mathrm{Rev} 15)$. It was detonated in tuff at a working point of $193 \mathrm{~m}$ below the surface. U9b is located in western Area 9 just east of the Yucca Fault. Figure 16 shows nearby holes and surface effects. Nearby tests include: Mad in U9a on 12/13/1961, Taunton in U9aa on 12/4/1962, Stillwater in U9c on 2/8/1962, Eel in U9m on 5/19/1962, Brazos in U9d on 3/8/1962, Roanoke in U9q on 10/12/1962, Rack in U9ap on 8/15/1968, simultaneous, same hole tests Branco and Branco-Herkimer in U2ew on 9/21/1983, and Starwort in U2bs on $4 / 26 / 1973$.

White collapsed to the surface 11 minutes after detonation. It formed a crater $16 \mathrm{~m}$ deep and $140 \mathrm{~m}$ in diameter. There were two vertical posttest holes associated with White: PS 1 and PS 2, both drilled to a depth of $223 \mathrm{~m}$. Both posttest holes were surveyed and sampled.

We have reviewed geology and test-related data, including information on the cavity and crater, and believe that complete collapse occurred quickly after detonation. The number of subsequent tests on Yucca Flat, and the entire NTS, gives us comfort that cavity collapse and crater formation should be complete. The ground surface above the U9b site has not changed over time, so it seems reasonable to conclude that the current configuration is stable. We have evaluated crater stability produced from cavity collapse, and have not considered later erosion effects. We rely on NSTec and DOE/NNSA/NSO to make decisions concerning safety issues related to reentering the crater area. 


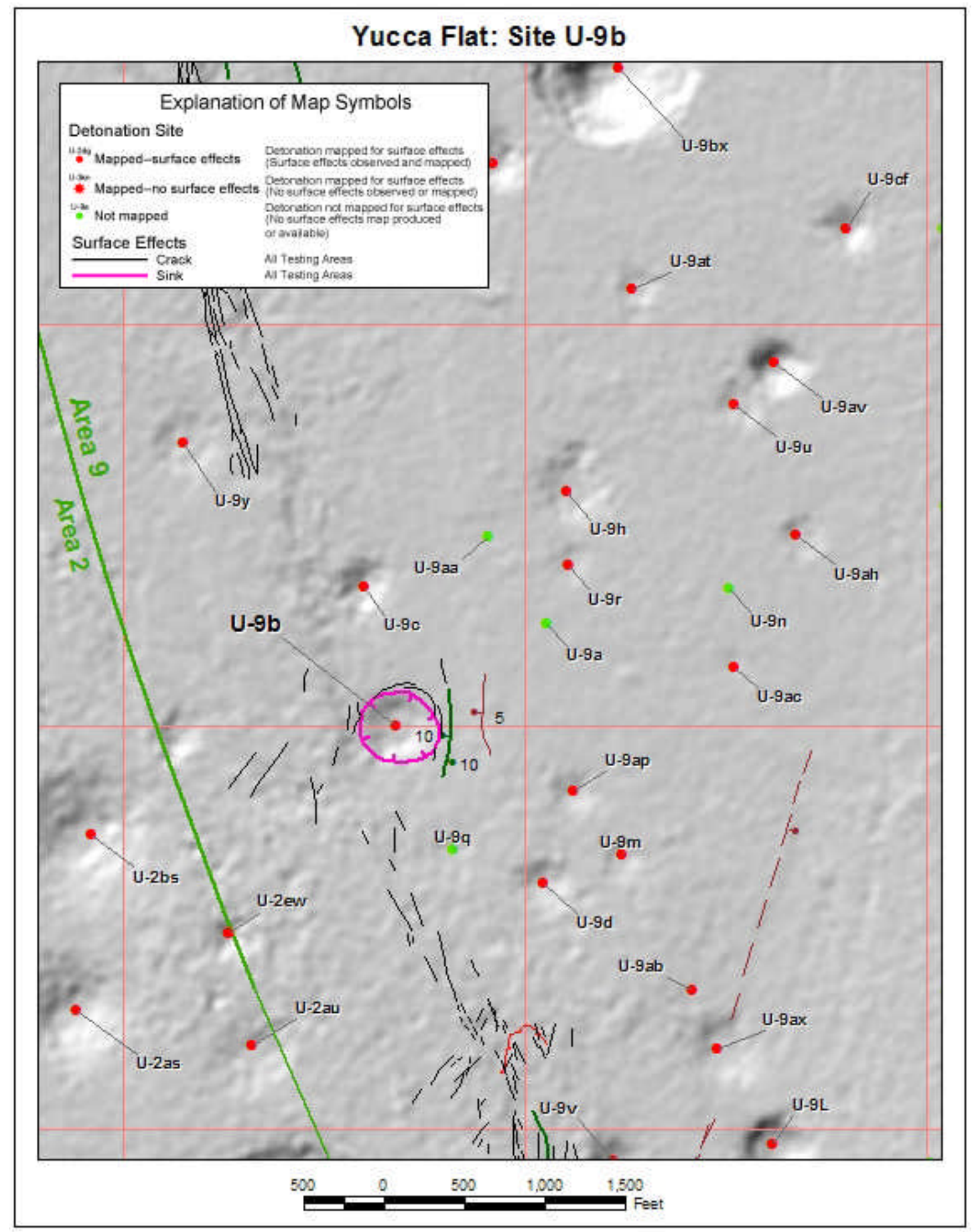

Figure 16. Surface effects map of hole U9b (Grasso, 2003). 


\section{Black \\ U9p}

The LLNL sponsored Black test was detonated in U9p on 4/27/1962. Black had an announced "low" yield (which equates to $<20 \mathrm{kt})(\mathrm{DOE} / \mathrm{NV}-209-\mathrm{Rev} 15)$. It was detonated in tuff at a working point of $218 \mathrm{~m}$ below the surface. U9p is located in southwestern Area 9, east of the Yucca Fault. Figure 17 shows nearby holes and surface effects. Nearby tests include: Player in U9cc on 8/27/1964, Silene in U9ck on 6/28/1973, Driver in U9ar on 5/7/1964, Terrine-White in U9bi-1 on 12/18/1969, simultaneous, separate holes tests Kootanai in U9w on 4/24/1963 and Paisano in U9w-1 on 4/24/1963, Backswing in U9aw on 5/14/1964, York in U9z on 8/24/1962, Tornillo in U9aq on 10/11/1963, Bogey in U9au on 4/17/1964, and Allegheny in U9x on 9/29/1962.

Black collapsed to the surface 21 minutes after detonation. It formed a crater $22 \mathrm{~m}$ deep and $120 \mathrm{~m}$ in diameter. There were two vertical posttest holes associated with Black, both collared within the collapse crater: PS 1, drilled to a depth of $231 \mathrm{~m}$, and PS 2, drilled to a depth of $244 \mathrm{~m}$. Both posttest holes were surveyed and sampled.

We have reviewed geology and test-related data, including information on the cavity and crater, and believe that complete collapse occurred quickly after detonation. The number of subsequent tests on Yucca Flat, and the entire NTS, gives us comfort that cavity collapse and crater formation should be complete. The ground surface above the U9p site has not changed over time, so it seems reasonable to conclude that the current configuration is stable. We have evaluated crater stability produced from cavity collapse, and have not considered later erosion effects. We rely on NSTec and $\mathrm{DOE} / \mathrm{NNSA} / \mathrm{NSO}$ to make decisions concerning safety issues related to reentering the crater area. 


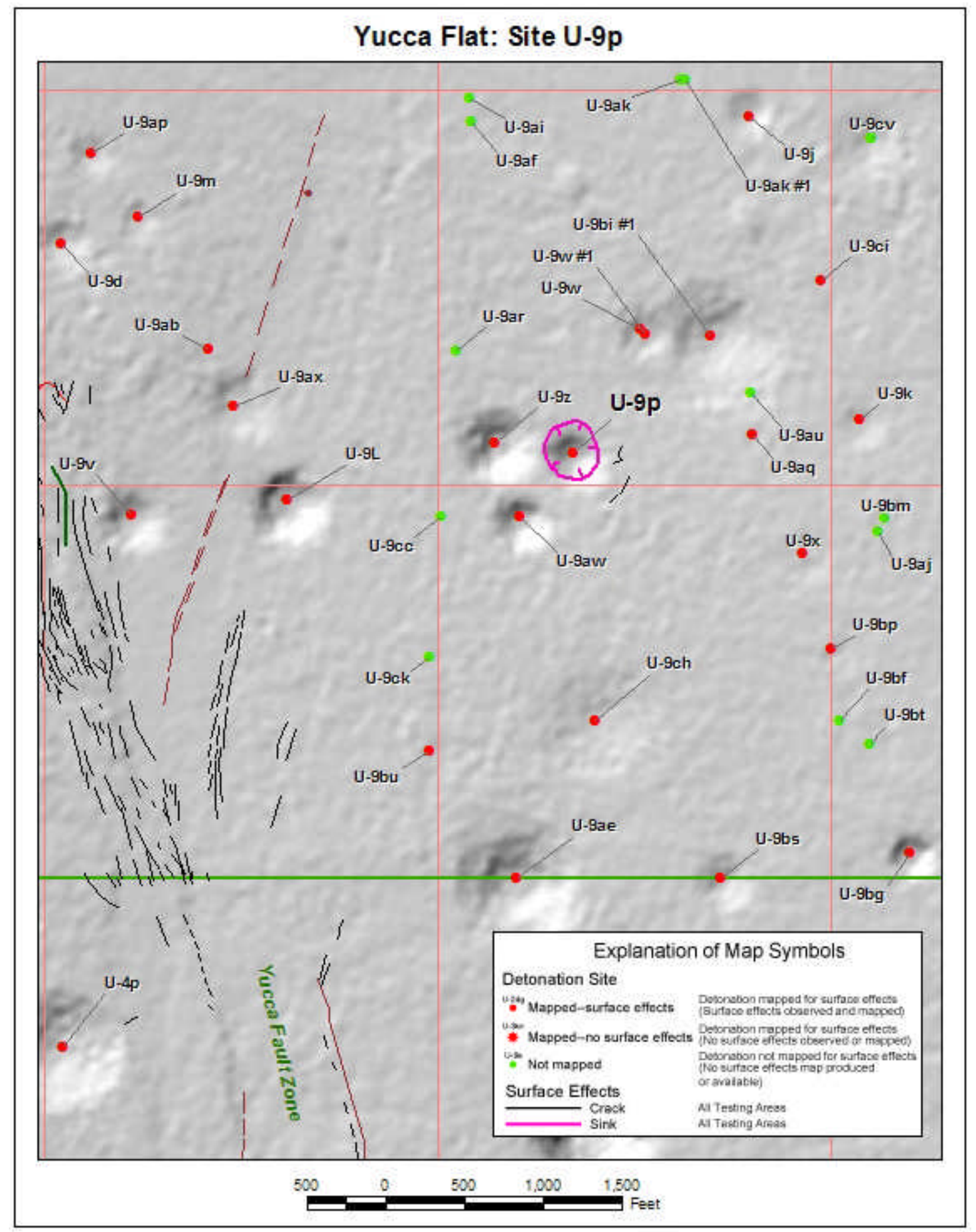

Figure 17. Surface effects map of hole U9p (Grasso, 2003). 


\section{York \\ U9z}

The LLNL sponsored York test was detonated in U9z on 8/24/1962. York had an announced "low" yield (which equates to $<20 \mathrm{kt})(\mathrm{DOE} / \mathrm{NV}-209-\mathrm{Rev} 15)$. It was detonated in tuff at a working point of $228 \mathrm{~m}$ below the surface. U9z is located in southwestern Area 9, east of the Yucca Fault. Figure 18 shows nearby holes and surface effects. Nearby tests include: Player in U9cc on 8/27/1964, Silene in U9ck on 6/28/1973, Driver in U9ar on 5/7/1964, Terrine-White in U9bi-1 on 12/18/1969, Passaic in U91 on 4/6/1962, Black in U9p on 4/27/1962, simultaneous, separate hole tests Kootanai in U9w and Paisano in U9w-1, both on 4/24/1963, and Backswing in U9aw on 5/14/1964.

York collapsed to the surface 5 minutes 30 seconds after detonation. It formed a crater $24 \mathrm{~m}$ deep and $152 \mathrm{~m}$ in diameter. There were two vertical posttest holes associated with York, both collared within the collapse crater: PS 1 and PS 2, both drilled to a depth of $250 \mathrm{~m}$, surveyed and sampled.

We have reviewed geology and test-related data, including information on the cavity and crater, and believe that complete collapse occurred quickly after detonation. The number of subsequent tests on Yucca Flat, and the entire NTS, gives us comfort that cavity collapse and crater formation should be complete. The ground surface above the U9z site has not changed over time, so it seems reasonable to conclude that the current configuration is stable. We have evaluated crater stability produced from cavity collapse, and have not considered later erosion effects. We rely on NSTec and $\mathrm{DOE} / \mathrm{NNSA} / \mathrm{NSO}$ to make decisions concerning safety issues related to reentering the crater area. 


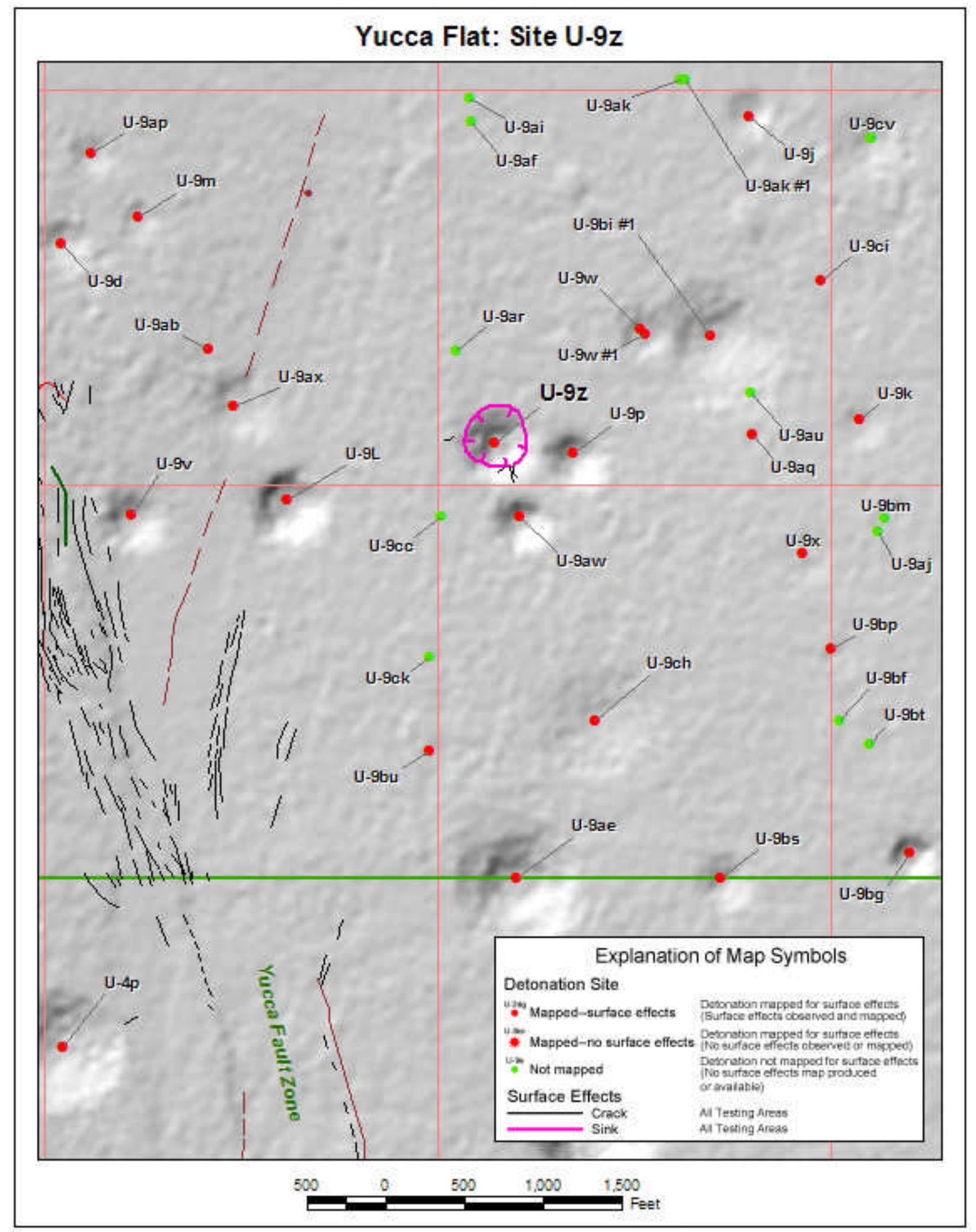

Figure 18. Surface effects map of hole U9z (Grasso, 2003). 


\section{Klickitat \\ U10e}

The LLNL sponsored Klickitat test was detonated in U10e on 2/20/1964. Klickitat was part of the Plowshare program. Klickitat had an announced yield of $70 \mathrm{kt}$ (DOE/NV-209-Rev 15). It was detonated in tuff at a working point of $492 \mathrm{~m}$ below the surface. U10e is located in southern Area 10, east of the Yucca Fault and north of the U9 ITS region. Figure 19 shows nearby holes and surface effects. Nearby tests include: Cup in U9cb on 3/26/1965, Asco in U10bc on 4/25/1978, Pera in U10bd on 9/8/1979, Havarti in U10bg on 8/5/1981, Shuffle in U10t on 4/18/1968, and Stanley in U10q on $7 / 27 / 1967$.

Klickitat collapsed to the surface 78 minutes after detonation. It formed a crater $38 \mathrm{~m}$ deep and $281 \mathrm{~m}$ in diameter. There were four vertical holes associated with Klickitat, all within the surface collapse crater. U10e \#1 is a satellite hole drilled to a depth of $518 \mathrm{~m}$. Three posttest holes include; PS 1, drilled to a depth of $512 \mathrm{~m}$, PS 2, drilled to a depth of $549 \mathrm{~m}$, and PS 3, drilled to a depth of $526 \mathrm{~m}$. The posttest holes were surveyed and sampled.

We have reviewed geology and test-related data, including information on the cavity and crater, and believe that complete collapse occurred quickly after detonation. The number of subsequent tests on Yucca Flat, and the entire NTS, gives us comfort that cavity collapse and crater formation should be complete. The ground surface above the U10e site has not changed over time, so it seems reasonable to conclude that the current configuration is stable. We have evaluated crater stability produced from cavity collapse, and have not considered later erosion effects. We rely on NSTec and DOE/NNSA/NSO to make decisions concerning safety issues related to reentering the crater area. 


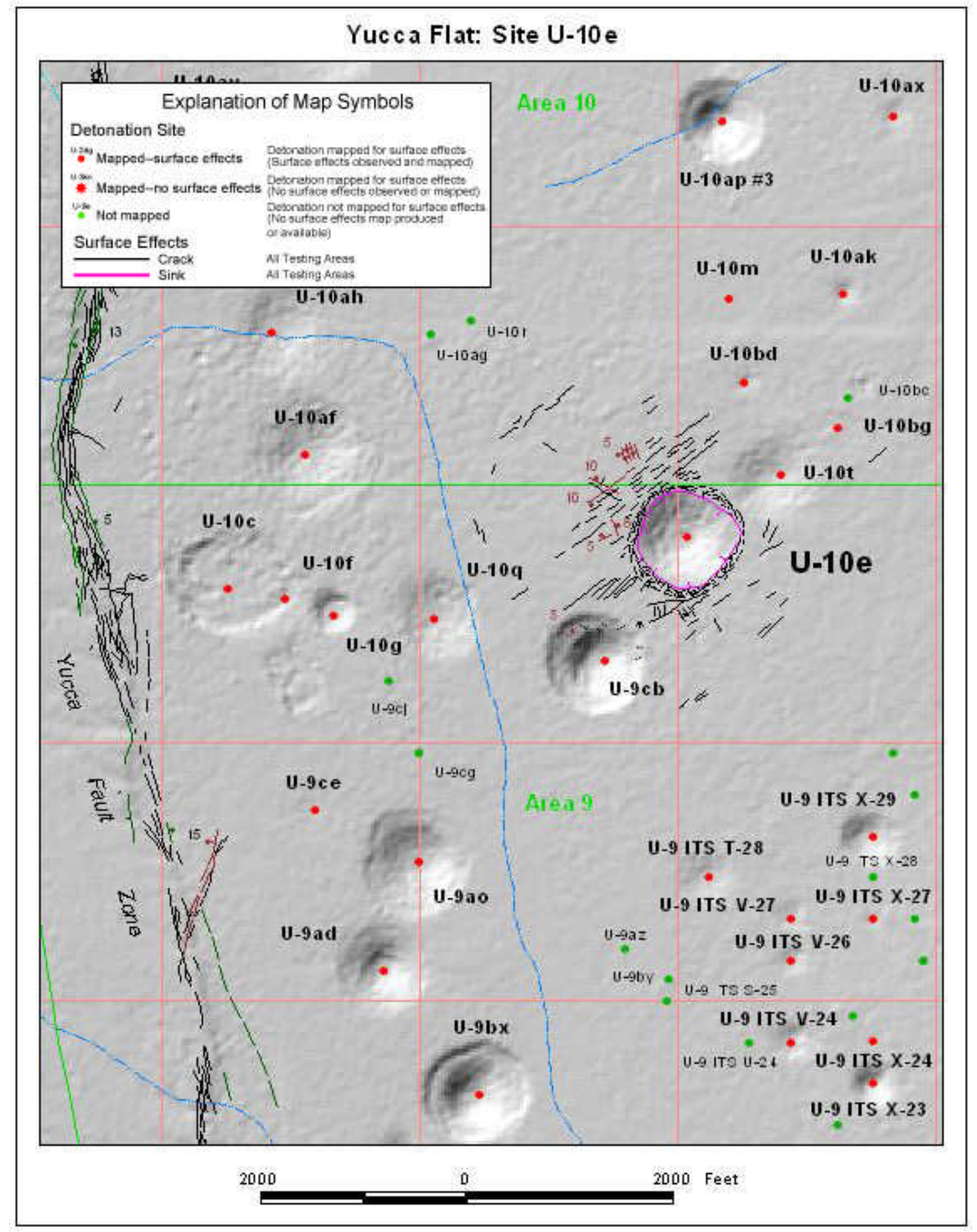

Figure 19. Surface effects map of hole U10e (Grasso, 2003). 


\section{Casselman U10g}

The LLNL sponsored Casselman test was detonated in U10g on 2/8/1963. Casselman had an announced "low" yield (which equates to $<20 \mathrm{kt}$ ) (DOE/NV-209-Rev 15). It was detonated in alluvium at a working point of $303 \mathrm{~m}$ below the surface. U10g is located in southern Area 10, just east of the Yucca Fault and north of the Area 9 ITS region. Figure 20 shows nearby holes and surface effects. Nearby tests include: simultaneous, same hole tests Gruyere and Gruyere-Gradino in U9cg on 8/16/1977, Santee in U10f on 10/27/1962, Turf in U10c on 4/24/1964, Stanley in U10q on $7 / 27 / 1967$, Alumroot in U9cj on 2/14/1973, Clymer in U9ce on 3/12/1966, and Yard in U10af on 9/7/1967.

Casselman collapsed to the surface 23 minutes after detonation. It formed a crater $22 \mathrm{~m}$ deep and $136 \mathrm{~m}$ in diameter. There were two vertical posttest holes associated with Casselman, both within the collapse crater: PS 1, drilled to a depth of $344 \mathrm{~m}$; and PS 2, drilled to a depth of $353 \mathrm{~m}$. The posttest holes were surveyed and sampled.

We have reviewed geology and test-related data, including information on the cavity and crater, and believe that complete collapse occurred quickly after detonation. The number of subsequent tests on Yucca Flat, and the entire NTS, gives us comfort that cavity collapse and crater formation should be complete. The ground surface above the U10g site has not changed over time, so it seems reasonable to conclude that the current configuration is stable. We have evaluated crater stability produced from cavity collapse, and have not considered later erosion effects. We rely on NSTec and DOE/NNSA/NSO to make decisions concerning safety issues related to reentering the crater area. 


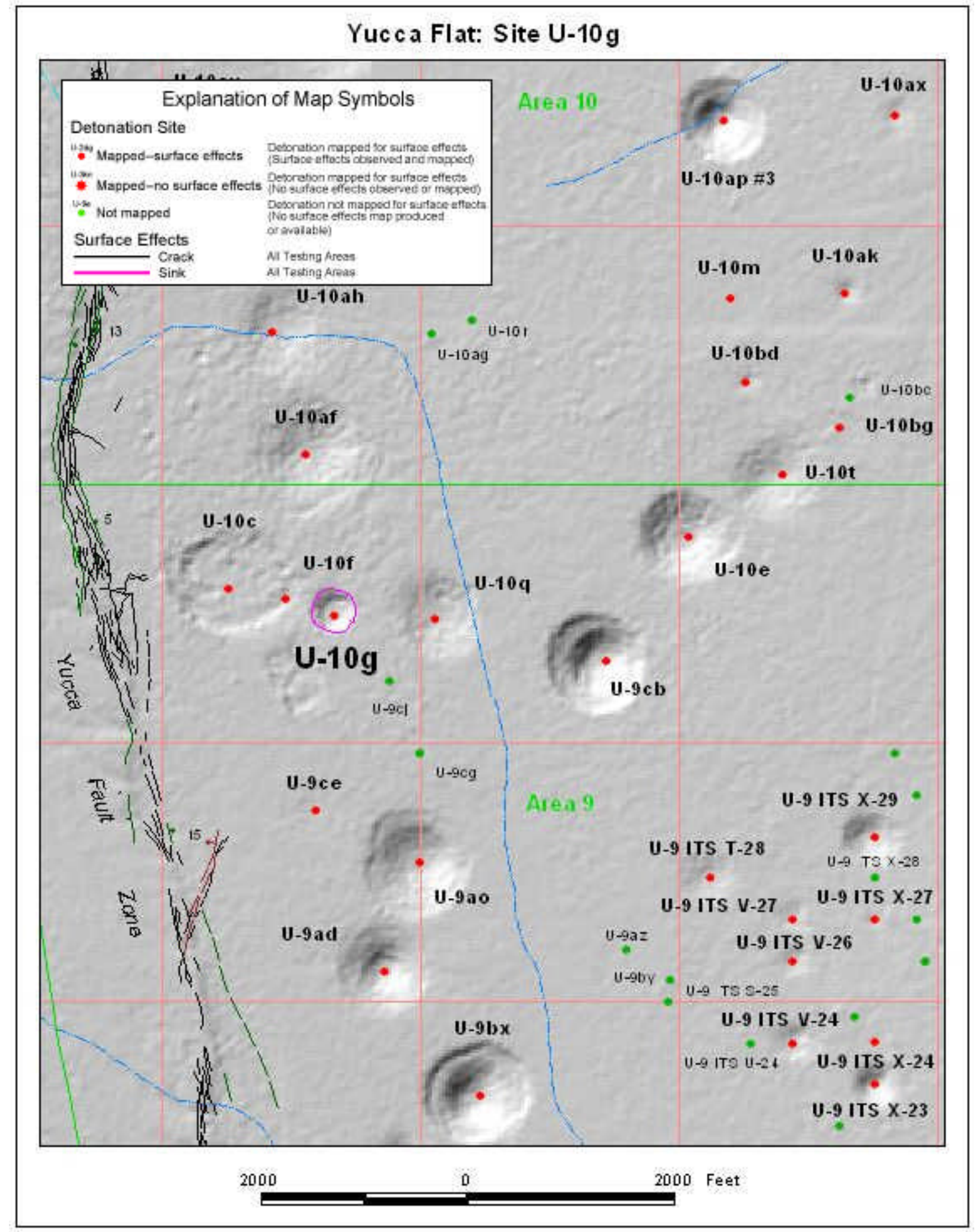

Figure 20. Surface effects map of hole U10g (Grasso, 2003). 


\section{References}

DOE (U.S. Department of Energy), 2000. United States Nuclear Tests July 1945 through September 1992, U.S. Department of Energy, Nevada Operations Office, Las Vegas, NV, DOE/NV-209, Rev 15.

Grasso, Dennis, 2003. GIS surface effects map archive, Nevada Test Site, Nevada, USGS OFR-03051 (searchable database at http://pubs.usgs.gov/of/2003/151/Archive/Start.htm).

Woodward, E.C., 1983. Riola Release Report, UCRL-53437, Lawrence Livermore National Laboratory, Livermore, California. 